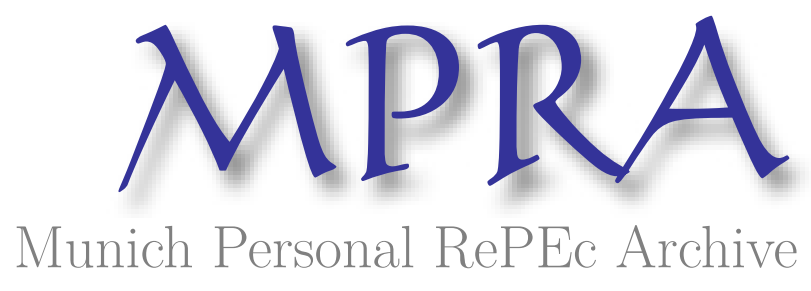

\title{
Trust and Law in Credit Markets
}

\author{
Asano, Koji
}

13 December 2018

Online at https://mpra.ub.uni-muenchen.de/90482/

MPRA Paper No. 90482, posted 13 Dec 2018 15:32 UTC 


\title{
Trust and Law in Credit Markets*
}

\author{
Koji Asano $^{\dagger}$
}

December 12, 2018

\begin{abstract}
This study examines the coevolution of trust and legal institutions in a model of competitive credit markets plagued by asymmetric information. When entrepreneurs' relative payoff to productive activities versus cheating is private information, uncivic ones, who intend to cheat, can enter credit markets and be cross-subsidized by civic ones, who engage in productive activities. To exploit this benefit, uncivic entrepreneurs demand weak legal enforcement through the political process. This rent-seeking behavior interacts with the formation of trust, generating an underdevelopment trap with weak enforcement and distrust. Technological advancement may encourage entrepreneurs' rent-seeking and aggravate distrust.
\end{abstract}

JEL Classification: O10, O16, Z13.

Keywords: culture, institutions, financial development, adverse selection.

${ }^{*}$ This paper is based on my Ph.D. dissertation at Osaka University. I am especially grateful to Katsuya Takii, Hajime Tomura, Junichiro Ishida, and Shingo Ishiguro for their valuable discussions and suggestions. I am also grateful to Koichi Futagami, Hirokazu Ishise, Ryosuke Okazawa, Akihisa Shibata, Takashi Shimizu, and the participants at the 2016 Asian Meeting of the Econometric Society, the 2016 Autumn Meeting of the Japanese Economic Association, the Osaka Workshop on Economics of Institutions and Organizations, and the 13th Annual Conference on Economic Growth and Development, along with the workshop and seminar participants at Osaka University, University of Tokyo, and Waseda University. I gratefully acknowledge the financial support from the Japan Society for the Promotion of Science through a Grant-in-Aid for JSPS Fellows No. 17J00739. All remaining errors are my own.

${ }^{\dagger}$ Graduate School of Economics, University of Tokyo, 7-3-1 Hongo, Bunkyo-ku, Tokyo 113-0033, Japan. E-mail: kojiasano@e.u-tokyo.ac.jp 


\section{Introduction}

Informational frictions cause dysfunctional credit markets and hinder economic prosperity. Given the severity of this issue, many empirical studies have attempted to identify the determinants of well-functioning credit markets. On the one hand, following La Porta et al. (1998), the literature emphasizes the influence of legal systems that enhance creditors' ability to seize collateral on credit market development. ${ }^{1}$ On the other hand, Guiso et al. (2004) demonstrate that trust, namely the faith that borrowers do not cheat based on their embedded civic values, encourages the supply of credit and that the effect of trust on the availability of financial contracts is larger in areas where legal institutions are weaker.

Despite the potential benefit of either strengthening the legal protection of creditors or cultivating trust, less developed economies fail to do both; the quality of institutions is positively associated with measures of trust, as shown among countries (Algan and Cahuc, 2014, Tables 2.6a), in European regions (Tabellini, 2008a), and in Italian provinces (Guiso et al., 2004). Why have some economies become trapped in a state of underdevelopment with weak institutions and distrust?

To better understand this issue, we examine how institutions and trust coevolve in a model of competitive credit markets plagued by asymmetric information. The presence of asymmetric information induces uncivic entrepreneurs intending to cheat to demand weak legal enforcement and secure their rents at the expense of other productive entrepreneurs. This rent-seeking behavior interacts with the formation of trust, leading to multiple steady states with different levels of institutional quality, trust, and aggregate output. We then show that the impact of technological improvement on an underdeveloped economy may be dampened owing to uncivic entrepreneurs' rent-seeking.

To show these results formally, we model credit markets in which entrepreneurs borrow funds and then decide secretly whether to invest the borrowed funds in a project (productive activity) or divert them to personal use (unproductive activity). Entrepreneurs differ only in

\footnotetext{
${ }^{1}$ See Djankov et al. (2007) and Besley et al. (2012).
} 
terms of their own civic values, which are private information. Civic entrepreneurs feel guilty for cheating, so that they are more attracted to investing in a project. By contrast, uncivic entrepreneurs prefer cheating to investing. Thus, in equilibrium, only civic entrepreneurs show productive entrepreneurial activity, thereby motivating us to measure the level of trust in the economy as the proportion of civic entrepreneurs.

The key institutional factor determined in the political process is the quality of the enforcement of the collateral that entrepreneurs pledge. Stronger enforcement increases the possibility that lenders seize collateral after default. If entrepreneurs' civic value is observable so that uncivic entrepreneurs are driven out of credit markets, there is no conflict of interests among entrepreneurs over the quality of enforcement. A sufficient quality of enforcement for productive entrepreneurial activity always receives political support. However, if entrepreneurs' value is unobservable, over-lending arises in equilibrium as in de Meza and Webb (1987), where financial contracts force civic entrepreneurs to cross-subsidize uncivic ones. $^{2}$ This cross-subsidization generates conflicts of interest between civic and uncivic entrepreneurs over the quality of enforcement; while strong enforcement is detrimental to uncivic entrepreneurs, it benefits civic entrepreneurs by lowering the degree of crosssubsidization. Thus, under a majority voting system, enforcement quality depends on the proportion of civic entrepreneurs. A high-trust economy in which civic entrepreneurs are widely dominant chooses the strongest enforcement. By contrast, a low-trust economy in which uncivic entrepreneurs are widely dominant chooses the weakest enforcement conditional on being funded, which implies that the equilibrium level of enforcement depends on entrepreneurs' ability to raise funds.

The political conflicts caused by credit market frictions interact with the formation of trust, when entrepreneurs' civic values are endogenously determined through parental education. Following Bisin and Verdier (2001) and Tabellini (2008b), we assume imperfect empathy: although parents care about the utilities of their children, they evaluate their

\footnotetext{
${ }^{2}$ In terms of modeling asymmetric information, our study is also related to Bester $(1985,1987)$, Besanko and Thakor (1987), and Martin (2009).
} 
children's behavior based on their own values. Such an approach implies that parents exert costly educational effort to instill their own values and this effort choice is influenced by the future circumstances of their children. This modeling generates complementarity between values and enforcement, leading to multiple steady states. If parents anticipate strong enforcement in the child's generation, they exert educational effort to make their children civic. That economy comprises a large proportion of civic children and thus will realize strong enforcement, meaning that the initial beliefs are justified. This steady state is characterized by a high level of trust, strong enforcement, and high aggregate output. If, instead, parents anticipate weak enforcement in the next generation, it discourages their incentives to exert civic education. The resulting economy is then composed of a large proportion of uncivic children and thus will lead to weak enforcement, implying that the initial expectations are again justified. This steady state features a low level of trust, weak enforcement, and low aggregate output.

An important mechanism of our model to generate an underdevelopment trap is that in a world with adverse selection, entrepreneurs who spend resources on unproductive activities attempt to lower institutional quality to secure their rents at the expense of productive entrepreneurs. This mechanism draws on the idea of Baumol (1990), which argues that entrepreneurs' rent-seeking activities can become pervasive and hinder economic development. ${ }^{3}$ We extend this idea to argue that entrepreneurs' rent-seeking behavior influences the formation of trust and credit market development.

This underlying mechanism of our model further derives two novel insights. First, although there is complementarity between trust and enforcement in the long run, they may be substitutes in the short run. During the transitional path on which uncivic entrepreneurs retain political power, higher trust improves contractual terms and benefits civic entrepreneurs, leading uncivic ones to exploit the benefits and weaken enforcement further. Second, the positive impact of technological improvement that enhances the profitability of productive

\footnotetext{
${ }^{3}$ Murphy et al. (1991) provides a formal model to investigate the implication of rent-seeking behavior for economic development.
} 
activities may be dampened because it induces uncivic entrepreneurs to exploit the benefits and weaken enforcement, which discourages parental education and the formation of trust. This negative effect of technological change may help explain why even though ideas and knowledge can spread so rapidly that any country has access to the innovations developed in advanced countries, some economies have been trapped in a state of underdevelopment.

A vast body of research has recognized the importance of civic values and trust in determining economic performance. ${ }^{4}$ Following the seminal work of Bisin and Verdier (2001), the theoretical works in this field have focused on the cultural transmission of values, such as those regarding trustworthiness (Francois and Zabojnik, 2005) and corruption (Hauk and Saez-Marti, 2002). ${ }^{5}$ In contrast to these studies, we treat institutions as endogenous to study their interactions with trust.

Our study also contributes to an extensive literature that has studied the political economy of formal institutions and financial development. ${ }^{6}$ Our emphasis on the effect of credit market frictions on institutional reform is in line with Aney et al. (2016), who show that the presence of adverse selection hinders the government from selecting surplus-maximizing policies. A key difference is that in our study, the resulting political failure interacts with cultural transmission and could have long-lasting negative consequences on the economy. Like our study, Ševčík (2012) and Matsuoka et al. (forthcoming) analyze the dynamics of legal protection for creditors and economic development. However, while they focus on capital accumulation, our emphasis is placed on the evolution of civic values.

There is a recent burgeoning literature on the coevolution of culture and formal institutions. ${ }^{7}$ Such an interplay is analyzed in a variety of contexts, including between cooperation

\footnotetext{
${ }^{4}$ See Putnam (1993), Fukuyama (1995), Knack and Keefer (1997), La Porta et al. (1997), Algan and Cahuc (2010), and Tabellini (2010).

${ }^{5}$ Kumar and Matsusaka (2009) develop an alternative model with which to study cultural evolution and the development process, in which they distinguish social capital that relies on personal networks from social capital useful for enforcing contracts with strangers.

${ }^{6}$ See Rajan and Zingales (2003), Pagano and Volpin (2005, 2006), Perotti and von Thadden (2006), and Biais and Mariotti (2009).

${ }^{7}$ See Alesina and Giuliano (2015) for an excellent survey and Bisin and Verdier (2017) for a theoretical analysis in the general setup.
} 
and legal institutions that enhance cooperation (Tabellini, 2008b), between the culture of work and redistribution policies (Alesina and Angeletos, 2005 and Bénabou and Tirole, 2006), between honesty norms and institutions that encourage trading (Bidner and Francois, 2011), and between cultural values and labor market institutions (Aghion et al., 2011, Michau, 2013 and Alesina et al., 2015). The most closely related works to our interests are Aghion et al. (2010) and Carlin et al. (2009), which focus on the coevolution of trust and government regulation. In Aghion et al. (2010), trust and entry regulation are substitutes because low-trust economies demand entry regulation to prevent uncivic entrepreneurs from imposing a negative externality, whereas under strong regulation entrepreneurs become uncivic to pay bribes and enter the market. Carlin et al. (2009) place financial markets at the center and show that whether trust and regulation are substitutes or complements depends on the value of social capital. The difference from these works is that in our study, the relationship between trust and enforcement changes depending on the timespan; they may be substitutes in the short run but they are complements in the long run. Moreover, our model sheds light on the mechanism through which technological change influences institutional quality and trust.

Outline: The remainder of the paper is organized as follows. Section 2 provides the framework of the static model in which civic values are exogenous. Section 3 analyzes the equilibrium of the static model and shows the one-way effect of trust on the quality of enforcement. Section 4 extends the model to the dynamic setting in which civic values are endogenously determined through parental education. The dynamic economy describes the divergence in development through the two-way effects between trust and enforcement. Section 5 concludes.

\section{The Static Model}

In this section, we describe the basic framework of the static model in which civic values are exogenously given, whereas the level of enforcement is an endogenous variable. 
There is a continuum of measure one of entrepreneurs and lenders. Both agents are risk-neutral and consume at the end of the period. Entrepreneurs are protected by limited liabilities. ${ }^{8}$ Each entrepreneur has a project requiring a fixed investment $I>0$. The project produces cash flows $R>0$ with probability $p \in(0,1]$ and nothing with probability $1-p$. Entrepreneurs have no funds and thus need to rely on external financing to run their projects. Lenders are deep-pocketed and willing to provide funds perfectly elastically at a fixed interest rate, which is normalized to zero.

Each entrepreneur is born with illiquid wealth $C>0$, which can be consumed only at the end of the period. Although this wealth cannot be transformed into cash, entrepreneurs can pledge it as collateral in the case of default. However, the pledge is enforced imperfectly: collateral is seized with probability $\tau \in[0,1]$ and is left to the entrepreneur with probability $1-\tau$. We interpret probability $\tau$ as a measure of institutional quality, with a higher value corresponding to better-quality institutions. The idea behind this interpretation is that the power of creditors against defaulting borrowers strengthens because of laws that improve creditor rights and their enforcement. $\tau$ is an endogenous variable and is selected by the simple majority rule before financial contracts are signed. In the political process, each agent votes on $\tau$ that maximizes his or her expected payoff and the voting decision is unobservable. We assume that $\tau$ can change without any cost to focus on its effect on financial contracts.

There is a moral hazard problem for entrepreneurs. After borrowing funds, each entrepreneur chooses either to invest them in projects or to steal them to consume. We assume that entrepreneurs who choose to cheat must default and lenders cannot distinguish default from cheating and that from project failure.

Entrepreneurs differ by their civic values, which affect their choice between investing and cheating. There are two types of entrepreneurs, denoted by $i \in\{G, B\}$, which corresponds to good (or civic) types and bad (or uncivic) types, respectively. When investing, the entrepreneur of type $i$ incurs a psychological effort cost, $\alpha^{i}$, with $\alpha^{B}>\alpha^{G}$. For simplicity, we

\footnotetext{
${ }^{8}$ We assume that the legal rules about limited liability cannot be changed in the political process.
} 
set $\alpha^{G}=0$. When cheating, the entrepreneur of type $i$ has a feeling of guilt and incurs a psychological cost, $\beta^{i}$, with $\beta^{G}>\beta^{B}>0$. The assumption $\beta^{B}>0$ implies that cheating is socially wasteful.

The proportion $\phi \in(0,1)$ of entrepreneurs are good types and $1-\phi$ of those are bad types. Each entrepreneur's type is private information but $\phi$ is common knowledge. While we take $\phi$ to be exogenously given in the static model, we allow $\phi$ to evolve as a result of family-led civic education in Section $4 .^{9}$

All borrowing and lending are intermediated through banks. There are a finite number of competitive, risk-neutral banks, which collect funds from lenders at the zero interest rate and offer entrepreneurs a menu of loan contracts. The loan contract specifies (i) that the entrepreneur borrows $I$, (ii) that banks receive $r$ and the entrepreneur receives $R-r$ when the investment succeeds, and (iii) that entrepreneurs pledge a proportion $k \in[0,1]$ of their wealth $C$ as collateral that banks try to seize in the case of default. Thus, if financing is secured, entrepreneurs of type $i$ have the following net expected utility: ${ }^{10}$

$$
U^{i}= \begin{cases}p(R-r)-(1-p) \tau k C-\alpha^{i} & \text { when investing } \\ b^{i}-\tau k C & \text { when cheating }\end{cases}
$$

where $b^{i} \equiv I-\beta^{i}$ denote the private benefit for an entrepreneur of type $i$ from cheating, with $I>b^{B}>b^{G}$. If financing is not secured, net utility is given by $U^{i}=0$.

To model credit market competition with adverse selection, we follow Rothschild and Stiglitz (1976) and consider the following two-stage game. In the first stage, banks design a menu of loan contracts and, in the second stage, entrepreneurs choose at most one of the contracts among those offered. To focus on the symmetric equilibrium, we assume that when

\footnotetext{
${ }^{9}$ Even if we endogenize $\phi$ in Section 4 , we focus on the equilibrium path on which $\phi$ is in the range $(0,1)$ by making Assumption 5 .

${ }^{10}$ The gross expected utility of entrepreneurs of type $i, \tilde{U}^{i}$, is given by $p(R-r+C)+(1-p)(1-k \tau) C-\alpha^{i}$ in the case of investing and $b^{i}+(1-\tau k) C$ in the case of cheating. After subtracting the consumption that the entrepreneurs would obtain without financing from their gross utility, we obtain their net utility; that is, $U^{i}=\tilde{U}^{i}-C$.
} 
more than one bank offers the same contract, they obtain the same share and composition of entrepreneurs that choose the contract and collect the same share of funds from lenders.

The timing of the events is as follows:

1. Each entrepreneur knows only his or her own type.

2. The quality of enforcement $\tau$ is determined by majoritarian voting.

3. Banks design financial contracts $(r, k)$, and then entrepreneurs apply for these contracts.

4. Each entrepreneur who borrows funds chooses between investing them in a project and stealing them.

5. Investment returns are realized, the realized outcome is shared as contracted, and consumption takes place.

We make two parametric assumptions. The first assumption guarantees that while for good entrepreneurs, running a project produces a positive value, for bad entrepreneurs, it does not:

Assumption $1 p R>I>p R-\alpha^{B}$.

Under Assumption 1, the first-best allocation (the allocation in the economy without moral hazard and adverse selection) is that good entrepreneurs make investment, whereas bad entrepreneurs do not.

The second assumption ensures that bad entrepreneurs find it beneficial to cheat even in the perfect enforcement case:

Assumption $2 b^{B}-C>0$.

Given $b^{B}=I-\beta^{B}$, Assumption 2 implies that collateral is insufficient to cover the cost of investment $(I>C)$ and repayment must be positive $(r>0)$. From (1) and Assumption 1, Assumption 2 also implies that in the economy with any level of enforcement, bad 
entrepreneurs have an incentive to apply for loans and choose to cheat rather than to invest. This means that in equilibrium, only good entrepreneurs invest funds in projects. When we define trust in this economy as banks' beliefs about the probability that an entrepreneur invests funds in projects, ${ }^{11}$ our measure of trust is consistent with the share of good entrepreneurs $\phi$. Therefore, hereafter, we refer to $\phi$ as the level of trust. We discuss the role of Assumption 2 in our model further at the end of Section 3.3.

Finally, we define an equilibrium. Our equilibrium concept is based on the perfect Bayesian equilibrium, requiring (i) that each agent's decisions are optimal, where enforcement $\tau$ and other agents' strategies and beliefs are taken as given, (ii) that agents' beliefs are consistent with Bayes' rule given the equilibrium strategies, whenever possible, and (iii) that the strength of enforcement $\tau$ is determined by majoritarian voting.

\section{Analysis of the Static Model}

This section analyzes the equilibrium of the static model. First, as a benchmark case, consider that entrepreneurs' type is observable in Section 3.1. Then, Section 3.2 characterizes the optimal financial contract in the presence of adverse selection. Section 3.3 investigates how the level of trust affects the quality of enforcement through the political process. Section 3.4 examines the comparative statics.

\subsection{Credit markets without adverse selection}

In this section, we consider the situation in which entrepreneurs' type is observable. Since banks behave competitively in loan markets, they design a financial contract that maximizes the payoff of entrepreneurs of type $i$ and provides a non-negative payoff for banks

\footnotetext{
${ }^{11}$ This definition is consistent with Gambetta's (2000) definition of trust. Gambetta (2000) defines trust as "the subjective probability with which an agent assesses that another agent or group of agents will perform a particular action" and states that "when we say we trust someone or that someone is trustworthy, we implicitly mean that the probability that he will perform an action that is beneficial or at least not detrimental to us is high enough for us to consider engaging in some form of cooperation with him."
} 
and the entrepreneurs. On the one hand, financing for bad entrepreneurs does not occur because a negative surplus arises either from investments in a project $\left(p R-I-\alpha^{B}<0\right.$ from Assumption 1) or from cheating $\left(\beta^{B}>0\right)$. On the other hand, for good entrepreneurs, financial contracts that provide them with incentives to invest are offered because if a good entrepreneur chooses cheating, yielding a negative surplus $\left(\beta^{G}>0\right)$, either the good entrepreneur or the bank must lose money in expectation.

Formally, given the strength of enforcement $\tau$, the optimal financial contract for good entrepreneurs is characterized as the solution of the following problem: choosing $(r, k)$ to maximize

$$
U^{G}=p(R-r)-(1-p) \tau k C
$$

subject to

$$
\begin{aligned}
& p(R-r)-(1-p) \tau k C \geq b^{G}-\tau k C, \\
& p(R-r)-(1-p) \tau k C \geq 0, \\
& p r+(1-p) \tau k C \geq I .
\end{aligned}
$$

The objective function (2) is the good entrepreneur's net expected payoff from (1). (3) is the incentive compatibility (IC) constraint, which requires that investing yields a higher payoff for good entrepreneurs than cheating. (4) and (5) are the individual rationality (IR) constraint for good entrepreneurs and the one for banks, respectively.

Since (5) is binding and banks break even, good entrepreneurs who borrow funds receive payoff $p R-I$, equivalent to the entire surplus of the project, and (4) is slack. Thus, any financial contract $(r, k)$ that satisfies (5) with equality, the feasibility constraint, $k \in[0,1]$, and (3) is indifferent to good entrepreneurs. Given that a higher $k$ relaxes (3), financing 
actually occurs if

$$
\underbrace{p R-b^{G}}_{\text {pledgeable income }}+\underbrace{\tau C}_{\text {collateral }} \geq I
$$

(6) means that when the sum of pledgeable income and collateral value exceeds the cost of financing, good entrepreneurs can obtain financing. This condition implies that if only the pledgeable income can cover the cost of financing (i.e., $p R-b^{G} \geq I$ ), pledging collateral is unnecessary; loan contracts that specify $k=0$ can be offered. However, if $p R-b^{G}<I$, collateral is necessary to compensate for a lack of pledgeable income. In this case, good entrepreneurs obtain financing by pledging some amount of collateral $(k>0)$.

Anticipating these financial contracts, agents vote on the strength of enforcement $\tau$. Each agent votes for $\tau$ that gives him or her the highest level of utility based on his or her preference. We assume that if some values of $\tau$ give agents the highest payoff, they randomize their choices. Lenders and bad entrepreneurs are indifferent to any $\tau$ because lenders earn zero profit and bad entrepreneurs obtain no financing, regardless of $\tau$. For good entrepreneurs, the desirable level of enforcement depends on the degree of pledgeability. If the pledgeable income is high such that collateral is unnecessary to secure financing $\left(p R-b^{G} \geq\right.$ $I$ ), any level of $\tau$ gives good entrepreneurs payoff $p R-I$. If the pledgeable income is low such that collateral is necessary $\left(p R-b^{G}<I \leq p R-b^{G}+C\right)$, they obtain payoff $p R-I$ as long as $\tau \geq \frac{I-p R+b^{G}}{C}$; when $\tau<\frac{I-p R+b^{G}}{C}$, they cannot obtain financing. Thus, if collateral does not matter, any level of $\tau$ is politically feasible, and if collateral matters, any $\tau \geq \frac{I-p R+b^{G}}{C}$ can be realized based on the demand from good entrepreneurs.

Proposition 1 Suppose that entrepreneurs' type is observable and that Assumption 1 holds. Assume $p R-b^{G}+C \geq I$. The level of enforcement takes any value in $\left[\max \left\{0, \frac{I-p R+b^{G}}{C}\right\}, 1\right]$. While good entrepreneurs invest in projects and receive their payoff $U^{G}=p R-I$, bad entrepreneurs obtain no financing and receive their payoff $U^{B}=0$.

Let us conclude the analysis of this section with two remarks. First, collateral matters because it makes up for the limited pledgeable income caused by the moral hazard problem. 
Second, in the stage of voting on the strength of enforcement, there is no conflict of interests between good and bad entrepreneurs. The political decision reflects only the preferences of good entrepreneurs, who demand a certain level of enforcement to secure financing. In the following sections, we show that when entrepreneurs' type is unobservable, collateral plays a role in reducing the cost of cross-subsidization, leading to a conflict of interests between good and bad entrepreneurs over the strength of enforcement.

\subsection{Credit markets with adverse selection}

Now, suppose that entrepreneurs' type is their private information. Given the level of trust $\phi$ and enforcement quality $\tau$, banks design loan contracts. We first can show that there is no separating equilibrium. If a separating equilibrium exists, only good entrepreneurs must obtain financing because the investment undertaken by good (bad) entrepreneurs yields a positive (negative) surplus from Assumption 1. However, from Assumption 2, bad entrepreneurs have incentives to pretend to be the good type and engage in cheating, which gives them a higher payoff than a payoff with no financing.

We then focus on a pooling equilibrium. An equilibrium pooling contract needs to satisfy the IC constraint (3), the IR constraint for good entrepreneurs (4), and the IR constraint for banks:

$$
\phi p r+(1-\phi p) \tau k C \geq I
$$

which is different from (5) because banks cannot distinguish good and bad entrepreneurs. From Assumption 1 and Assumption 2, bad entrepreneurs always engage in cheating and earn a positive payoff, $U^{B}=b^{B}-\tau C>0$, making their IR constraint slacking. Because banks compete to attract good entrepreneurs, the equilibrium pooling contract is characterized as the solution of the problem that chooses $(r, k)$ to maximize good entrepreneurs' payoff (2) subject to the constraints (3), (4), and (7).

Given that (7) is binding and banks earn zero profit, good entrepreneurs prefer contracts 
that require more collateral (higher $k$ ) and smaller repayments (lower $r$ ) because pledging collateral is less costly to good entrepreneurs, who have a lower probability of default, compared with bad ones, and reduces the cost of cross-subsidization. Thus, equilibrium contracts require that collateral is fully pledged, $k=1$, and repayment $r$ is determined by (7) satisfied with equality.

Financing occurs if the remaining two constraints are satisfied. The first constraint (3) becomes

$$
\phi\left(p R-b^{G}\right)+\tau C \geq I
$$

which requires that the sum of the expected pledgeable income provided by good entrepreneurs and the collateral value is larger than the cost of financing. Compared with the constraint without adverse selection (6), (8) is more restrictive because the presence of bad entrepreneurs reduces the expected pledgeable income. The second constraint (4) can be rewritten as

$$
U^{G}=p R-I-\underbrace{\frac{1-\phi}{\phi}(I-\tau C)}_{\text {cost of adverse selection }} \geq 0
$$

which implies that good entrepreneurs' payoff is increasing in $\phi$ and can be negative. A lower $\phi$ increases the cost of cross-subsidizing bad entrepreneurs and may drive good ones out of credit markets.

The following proposition characterizes the equilibrium financial contract.

Proposition 2 Suppose that Assumptions 1-2 hold. If $\tau$ is high such that $\tau \geq \underline{\tau}(\phi)$ for any $\phi \geq \underline{\phi}$, where

$$
\underline{\tau}(\phi) \equiv \begin{cases}\frac{I-\phi p R}{C(1-\phi)} & \text { if } \phi \leq \frac{I-b^{G}}{p R-b^{G}}, \\ \frac{I-\phi\left(p R-b^{G}\right)}{C} & \text { if } \frac{I-b^{G}}{p R-b^{G}}<\phi \leq \frac{I}{p R-b^{G}}, \\ 0 & \text { if } \frac{I}{p R-b^{G}}<\phi,\end{cases}
$$




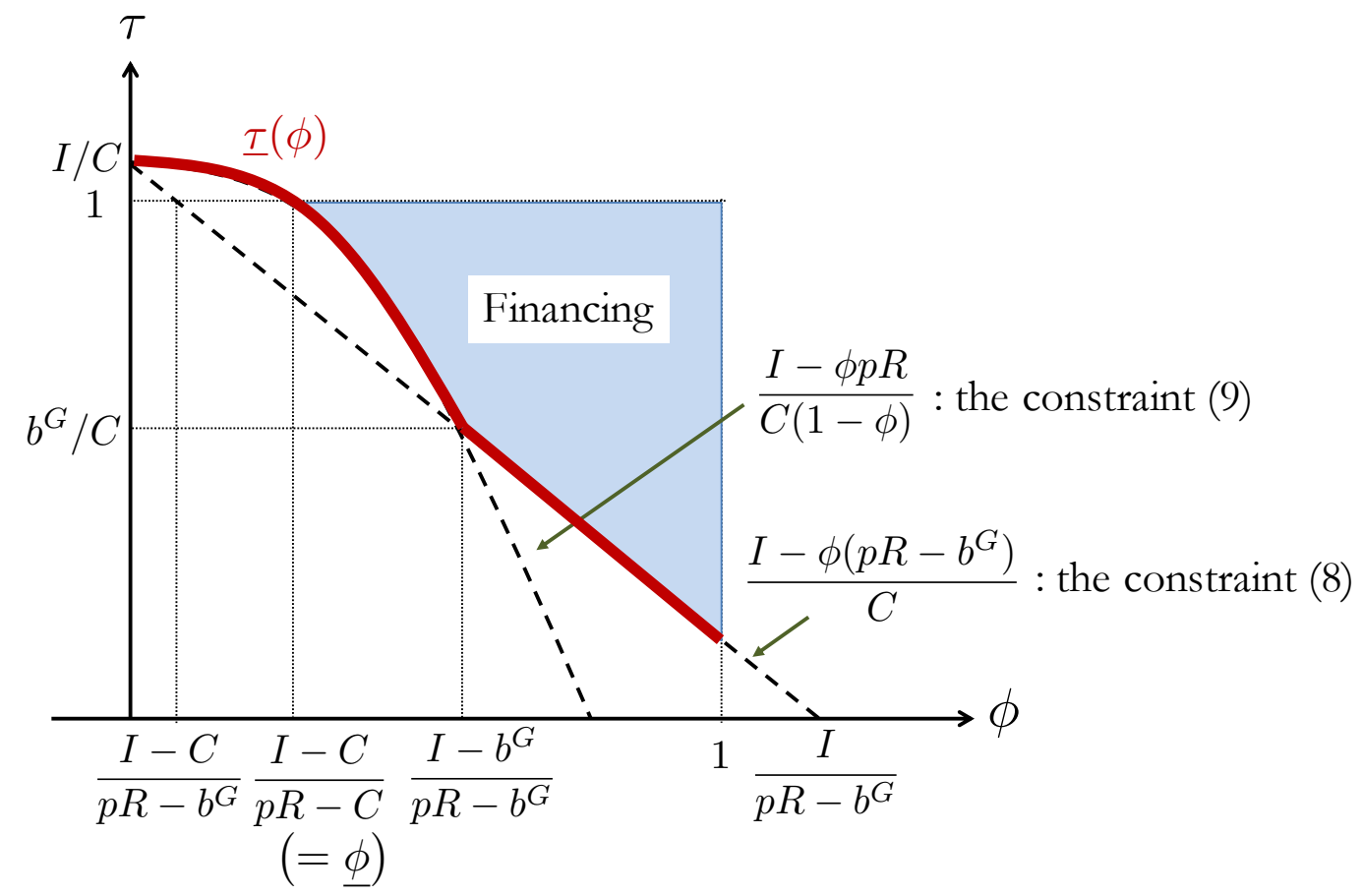

Figure 1: Financing conditions

and

$$
\underline{\phi} \equiv \max \left\{\frac{I-C}{p R-C}, \frac{I-C}{p R-b^{G}}\right\}>0,
$$

then both types of entrepreneurs obtain financing by applying for a pooling contract:

$$
(r, k)=\left(\frac{I-(1-\phi p) \tau C}{\phi p}, 1\right)
$$

Otherwise, no financing occurs.

Proof. See Appendix A.

Proposition 2 shows that financing occurs only in the shaded region in Figure 1. If the level of trust $\phi$ is lower than the threshold $\underline{\phi}$, either (8) or (9) must be violated for any $\tau$, leading to the breakdown of credit markets. If $\phi$ is above the threshold $\underline{\phi}$, pooling contracts can be offered depending on the strength of enforcement $\tau$. When $\phi$ is low such that $\phi \leq \frac{I-b^{G}}{p R-b^{G}}$, the cost of cross-subsidizing bad entrepreneurs is so high that it is more difficult to satisfy good entrepreneurs' IR constraint (9) than their IC constraint (8). This implies that for $\tau \geq \underline{\tau}(\phi)$, where $\underline{\tau}(\phi)$ is determined by (9) holding as an equality, financing 
occurs. When $\phi$ is high such that $\phi>\frac{I-b^{G}}{p R-b^{G}}$, it is more difficult to provide good entrepreneurs with incentives to invest and satisfy the IC constraint (8) than to meet their IR constraint (9). In this case, the threshold $\underline{\tau}(\phi)$ is determined by (8) holding as an equality, and for any $\tau$ above the threshold, entrepreneurs obtain financing. Although the binding constraint changes depending on $\phi$, a higher $\phi$ relaxes both constraints (8) and (9) further, decreasing the lower bound of enforcement quality $\underline{\tau}(\phi)$. If $\phi$ exceeds a certain level, $\frac{I}{p R-b^{G}}$, then the threshold reaches the lowest level 0 .

Proposition 2 highlights several differences from the situation without adverse selection. First, bad entrepreneurs can obtain financing and their cheating reduces the social surplus; in other words, over-lending arises as in de Meza and Webb (1987). Second, pledging collateral matters because it reduces the cost of adverse selection. This effect leads to the equilibrium contract that requires entrepreneurs to pledge the full amount of collateral $(k=1)$. Third, the required level of enforcement to secure financing can be higher because the possibility that bad entrepreneurs obtain financing decreases the expected pledgeable income and aggravates the moral hazard problem. Fourth, as Guiso et al. (2004) emphasize, the level of trust affects financial development. A certain level of trust (i.e., $\phi \geq \underline{\phi}$ ) is necessary to sustain the working of credit markets, and a higher $\phi$ reduces the cost of financing (captured by a decrease in repayment $r$ ). Moreover, the effect of higher trust on the cost of financing is larger in an

economy with weaker enforcement (i.e., $\frac{\partial^{2} r}{\partial \phi \partial \tau}>0$ ). In the next section, we show that despite the large potential benefit of strengthening enforcement, the low-trust economy does not increase $\tau$ in the equilibrium.

\subsection{The equilibrium quality of enforcement}

Given the level of trust $\phi$, the strength of enforcement $\tau$ is determined by majoritarian voting. While lenders earn zero profit for any $\tau$, a conflict of interests between different types of entrepreneurs over $\tau$ emerges due to adverse selection. 
On the one hand, from (9), good entrepreneurs' policy preferences are given by

$$
U^{G}= \begin{cases}p R-\frac{I}{\phi}+\frac{1-\phi}{\phi} \tau C & \text { if } \phi \geq \underline{\phi} \text { and } \tau \geq \underline{\tau}(\phi) \\ 0 & \text { otherwise }\end{cases}
$$

They receive a higher payoff when they obtain financing than when they do not, and conditional on financing, they prefer a higher $\tau$ because stronger enforcement reduces the degree of cross-subsidization. This means that the perfect level of enforcement, $\tau=1$, maximizes good entrepreneurs' payoff (13) if $\phi \geq \underline{\phi}$. On the other hand, bad entrepreneurs' policy preferences are given by

$$
U^{B}= \begin{cases}b^{B}-\tau C & \text { if } \phi \geq \underline{\phi} \text { and } \tau \geq \underline{\tau}(\phi), \\ 0 & \text { otherwise. }\end{cases}
$$

They prefer being funded to not being funded, as with good entrepreneurs. However, conditional on financing, bad entrepreneurs prefer a lower $\tau$ because weaker enforcement decreases the probability of losing collateral after cheating. As a result, if $\phi \geq \underline{\phi}$, the lowest level of enforcement, $\tau=\underline{\tau}(\phi)$, maximizes bad entrepreneurs' payoff (14).

The equilibrium level of enforcement depends on the proportion of good entrepreneurs $\phi$, as shown in Figure 2. When $\phi>\max \{1 / 2, \underline{\phi}\}$, good entrepreneurs are in the majority, and $\tau=1$ is selected according to their preferences (13). Thus, we refer to the situation in which good entrepreneurs become the majority as the strong enforcement regime. When $\underline{\phi} \leq \phi \leq 1 / 2$, bad entrepreneurs are in the majority, and $\tau=\underline{\tau}(\phi)$ is chosen according to their preferences (14). ${ }^{12}$ We call the situation that bad entrepreneurs constitute the majority the weak enforcement regime. When $\phi<\underline{\phi}, \tau$ is indeterminate and does not affect the equilibrium outcome because no financing is inevitable.

\footnotetext{
${ }^{12}$ We assume that when $\phi=1 / 2$, bad entrepreneurs have the political power to determine $\tau$. This assumption does not change our conclusion.
} 


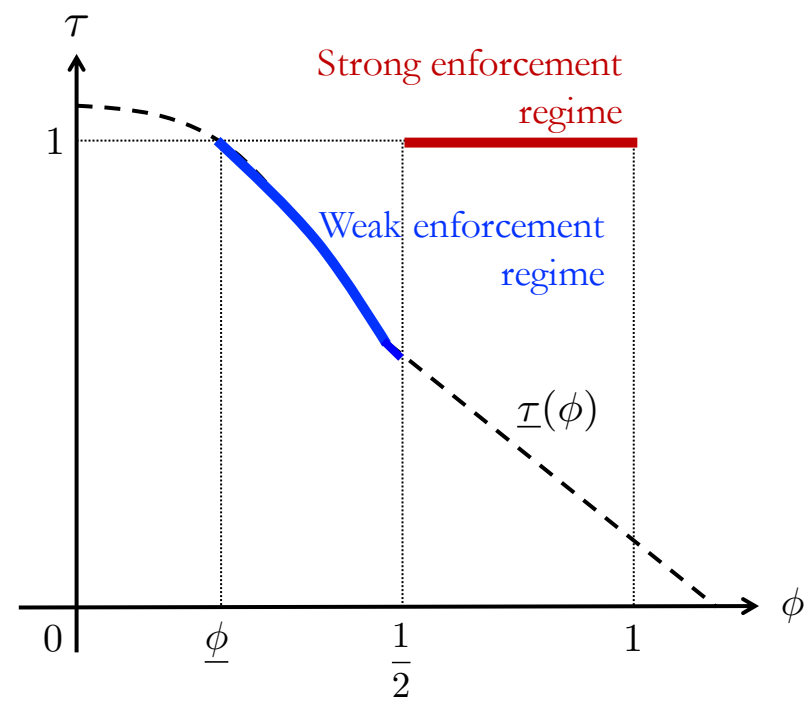

Figure 2: Equilibrium level of enforcement

Proposition 3 Suppose that Assumptions 1-2 hold. If $\phi>\max \{1 / 2, \underline{\phi}\}$, the equilibrium level of enforcement is given by $\tau=1$. If $\underline{\phi} \leq \phi \leq 1 / 2$, then it is $\tau=\underline{\tau}(\phi)$ given by (10). Otherwise, the equilibrium level of enforcement takes any value in $[0,1]$.

Proposition 3 exhibits the non-linear relationship between the level of trust and quality of enforcement. When the level of trust is low, a higher level of trust enhances entrepreneurs' ability to secure financing and thus allows bad entrepreneurs to weaken enforcement. However, once the economy cultivates trust up to a certain level, good entrepreneurs obtain political power and set strong enforcement.

Discussion of Assumption 2: If Assumption 2 is violated and the collateral value is high such that $C>b^{B}$, the separating equilibrium emerges for $\tau>b^{B} / C$; with a sufficiently high level of enforcement, cheating is not attractive for bad entrepreneurs and they choose to exit the credit markets. In this case, the issue of cross-subsidization is resolved, and so good entrepreneurs can receive loan contracts that give them the entire surplus $p R-I$ as in the situation without adverse selection. This implies that when $\phi \geq 1 / 2$, good entrepreneurs support strong enforcement that satisfies $\tau>b^{B} / C$, and the resulting economy is free from the effect of adverse selection. Perhaps more surprisingly, the same thing happens when $\phi$ is sufficiently low that the pooling equilibrium does not exist for any $\tau$. Because bad 


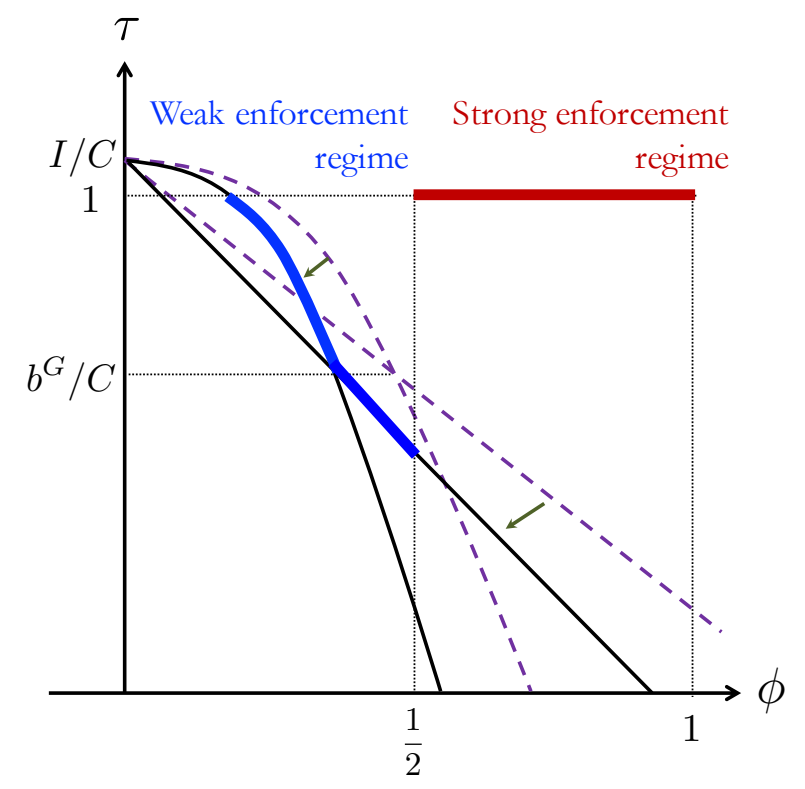

(a) The effect of an increase in $R$

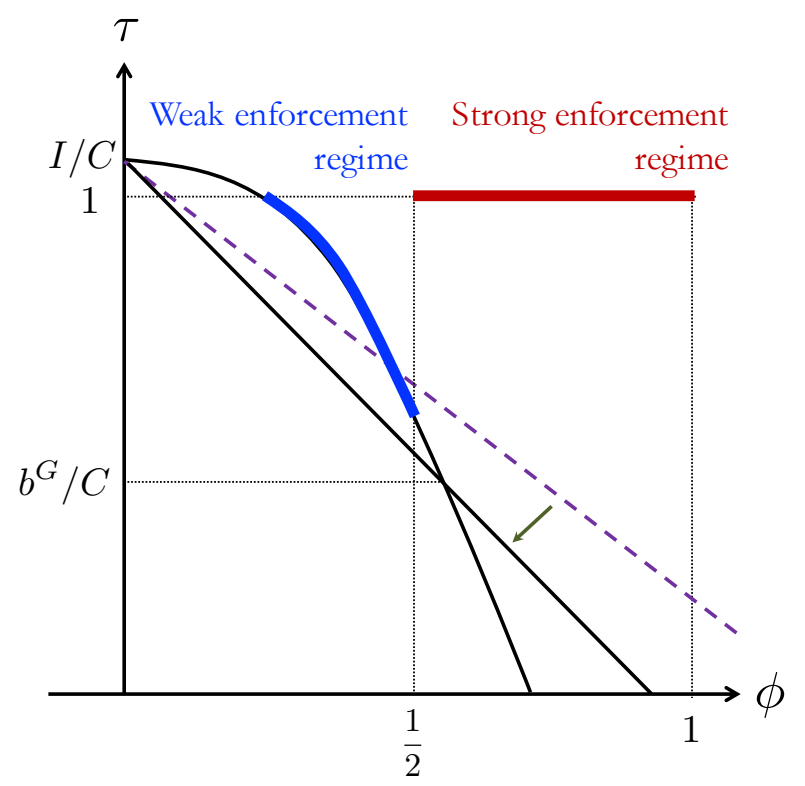

(b) The effect of a decrease in $b^{G}$

Figure 3: Comparative statics in the static model

entrepreneurs do not obtain financing regardless of $\tau$, the political decision reflects only the preferences of good entrepreneurs, who demand strong enforcement to allow for the separating equilibrium $\left(\tau>b^{B} / C\right)$. Thus, while the economy achieves the first-best allocation in a low- or a high-trust economy, over-lending takes place in the case of an intermediate level of trust.

\subsection{Comparative statics}

First, we consider the effect of technological advancements captured by an increase in project return $R .^{13}$ This effect is shown in Figure 3a. A higher $R$ not only raises the good entrepreneur's payoff, which relaxes (9), but also increases the pledgeable income, which relaxes (8). As a result, these effects enhance entrepreneurs' ability to attract funds. However, the beneficial effects on good entrepreneurs can be exploited by bad entrepreneurs through the political process. In the weak enforcement regime, the increase in $R$ weakens enforcement and benefits bad entrepreneurs.

\footnotetext{
${ }^{13} \mathrm{An}$ increase in $p$ and a decrease in $I$ are also interpreted as technological progress. These changes have the same effect as an increase in $R$.
} 
Next, we consider an increase in the feeling of guilt from cheating $\beta^{G}$ or a decrease in $b^{G}$. This captures the effect of public education, which plays an important role in nurturing civic virtues. As shown in Figure 3b, while a lower $b^{G}$ does not directly affect good entrepreneurs' payoff, it discourages them from cheating and relaxes (8). This implies that if the economy is under the weak enforcement regime and (8) is binding before the change in $b^{G}\left(\frac{I-b^{G}}{p R-b^{G}}<\phi \leq\right.$ $\frac{1}{2}$ ), the equilibrium level of enforcement decreases after the change because bad entrepreneurs understand that credit markets still work even if enforcement is further weakened.

\section{Dynamics}

We extend the static model developed in Section 2 into the dynamic setting by allowing for intergenerational cultural transmission. Parents can influence the civic values of their children, and through such parental education, the level of trust $\phi$ evolves over time. Section 4.1 describes the dynamic setting. Section 4.2 considers cultural transmission in the benchmark case in which entrepreneurs' type is observable. Section 4.3 analyzes parents' incentives to educate their children when entrepreneurs' type is unobservable. Section 4.4 shows that the complementarity between trust and enforcement leads to multiple steady states. In contrast to the result of the static model, the level of trust is positively associated with enforcement quality in the long run, which is consistent with the empirical regularity. Section 4.5 characterizes the transitional dynamics, where trust and enforcement can be substitutes. Section 4.6 studies the comparative statics.

\subsection{Dynamic setting}

Time is discrete, indexed by $t=0,1,2, \ldots$, and goes on forever. In every period, a continuum of mass one of lenders and entrepreneurs are born. Lenders live for only one period, are born with a sufficiently large amount of funds, and provide them perfectly elastically at a fixed interest rate 0. Entrepreneurs live for two periods (young and old). In each generation, one 


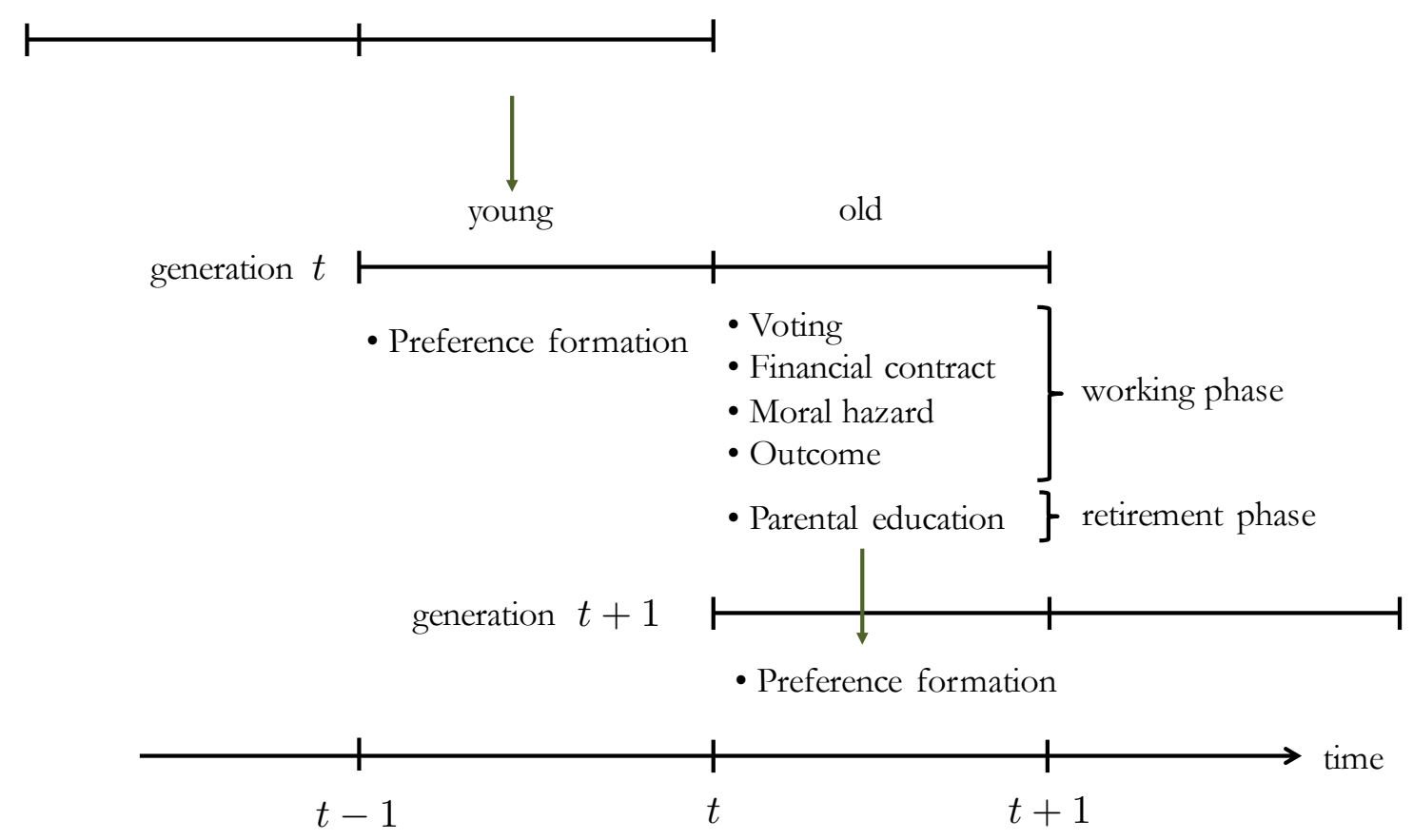

Figure 4: Time structure of the overlapping generations model

young entrepreneur is born from each old entrepreneur. Figure 4 shows the time structure. Entrepreneurs form their own civic value when young. When they are old, there are two phases: the working phase and retirement phase. During the working phase in period $t$, entrepreneurs experience the same events as those in the static model of Section 2; they receive illiquid wealth $C$, know their own type, vote on the level of enforcement $\tau_{t}$, apply for financial contracts $\left(r_{t}, k_{t}\right)$ offered by banks, face moral hazard, and consume. We assume that once wealth is consumed, it disappears. During the retirement phase in period $t$, each old entrepreneur exerts costly educational effort to instill civic values in his or her child individually. An old entrepreneur with type $i \in\{G, B\}$ can increase the probability that the child becomes good by $f_{t}^{i} \geq 0$ by incurring the psychological cost $\frac{1}{2 \gamma}\left(f_{t}^{i}\right)^{2}$ with $\gamma>0 .{ }^{14}$ After receiving parental education, the young entrepreneur knows only his or her own type. We assume that the level of educational effort is unobservable.

Following Bisin and Verdier (2001) and Tabellini (2008b), we adopt the "imperfect empathy" approach: parents are altruistic and take into account the utility of their children;

\footnotetext{
${ }^{14}$ If parents can increase the probability that their children become bad, namely $f_{t}^{i}$ can take negative values, the proportion of good entrepreneurs can be smaller. However, the qualitative result does not change.
} 
however, they evaluate their children's actions based on their own preferences. This approach reflects the idea that parents are paternalistic. Let $U_{t-1}^{i}$ and $V_{t}^{i j}$ denote the expected net payoff to type- $i$ entrepreneurs of generation $t-1$ deriving from their own activity in the working phase and the one deriving from the activity in the working phase of their type- $j$ children, respectively. The expected lifetime utility of a type- $i$ entrepreneur of generation $t-1$ is given by

$$
U_{t-1}^{i}+\left(\delta+f_{t-1}^{i}\right) V_{t}^{i G}+\left(1-\delta-f_{t-1}^{i}\right) V_{t}^{i B}-\frac{\left(f_{t-1}^{i}\right)^{2}}{2 \gamma}
$$

where $\delta \in(0,1)$ is the probability that a good child is born naturally.

Let $\phi_{t}$ denote the proportion of good entrepreneurs of generation $t$. Through parental education, the proportion of good entrepreneurs evolves according to

$$
\phi_{t}=\phi_{t-1}\left(\delta+f_{t-1}^{G}\right)+\left(1-\phi_{t-1}\right)\left(\delta+f_{t-1}^{B}\right), \text { for any } t>0
$$

Because of the law of large numbers, the measure $\phi_{t-1}\left(\delta+f_{t-1}^{G}\right)$ of type- $G$ young entrepreneurs are born from type- $G$ old entrepreneurs and the measure $\left(1-\phi_{t-1}\right)\left(\delta+f_{t-1}^{B}\right)$ of type- $G$ young entrepreneurs are born from type- $B$ old entrepreneurs. Given $f_{t-1}^{i} \geq 0$, (16) implies that $\delta$ is a minimum proportion of good entrepreneurs. We assume that an entrepreneur of the initial generation $(t=0)$ becomes good with probability $\phi_{0}$ and bad with probability with $1-\phi_{0}$, where $\phi_{0}$ is exogenously given and common knowledge.

We assume that banks have no information about the entrepreneurs of past generations, so that banks cannot have beliefs about an entrepreneur's type that depend on the dynasty. This simplifies our analysis because all old entrepreneurs of generation $t$ are the same from banks' perspective, and so they must believe that they provide funds to good entrepreneurs with probability $\phi_{t}$ and bad ones with probability $1-\phi_{t}$. Thus, the payoff-relevant state variable is the level of trust $\phi_{t}$. 


\subsection{Cultural transmission in credit markets without adverse selec- tion}

As a benchmark case, we analyze the evolution of trust when entrepreneurs' type is observable. Because old entrepreneurs influence their children only through education, their lifetime utility (15) implies that their decisions in the working phase are made independently of their decisions in the retirement phase. This allows us to apply the result of Section 3.1 to this dynamic setting. As shown in Proposition 1, although the strength of enforcement $\tau_{t}$

can take any value in $\left[\max \left\{0, \frac{I-p R+b^{G}}{C}\right\}, 1\right]$, good entrepreneurs always invest in projects and receive their payoff $U_{t}^{G}=p R-I$, and bad entrepreneurs obtain no financing and earn their payoff $U_{t}^{B}=0$.

Next, consider parental education. From (15), the parental optimization problem of a type- $i$ old entrepreneur becomes

$$
\max _{f_{t-1}^{i} \in[0,1-\delta]}\left(\delta+f_{t-1}^{i}\right) V_{t}^{i G}+\left(1-\delta-f_{t-1}^{i}\right) V_{t}^{i B}-\frac{\left(f_{t-1}^{i}\right)^{2}}{2 \gamma} .
$$

When the child becomes good, the old entrepreneur's payoff depends on his or her type $i$ because of imperfect empathy, which induces him or her to evaluate the child's action based on his or her own values. While old entrepreneurs of type $G$ receive the same utility as the young, i.e., $V_{t}^{G G}=U_{t}^{G}=p R-I$, old entrepreneurs of type $B$ consider that the investment undertaken by their children entails the psychological cost $\alpha^{B}$, i.e., $V_{t}^{B G}=p R-I-\alpha^{B}$, although their children actually do not incur such a cost. When the child becomes bad, both types of old entrepreneurs receive a zero payoff because bad entrepreneurs cannot obtain financing: $V_{t}^{G B}=V_{t}^{B B}=U_{t}^{B}=0$.

(17) implies that old entrepreneurs of type $B$ do not have an incentive to educate their children, that is, $f_{t-1}^{B}=0$ for any period because $V_{t}^{B G}<V_{t}^{B B}$ from Assumption 1. By contrast, old entrepreneurs of type $G$ have an incentive to exert educational effort because $V_{t}^{G G}>V_{t}^{G B}$ from Assumption 1. When the cost of education is sufficiently large such that 


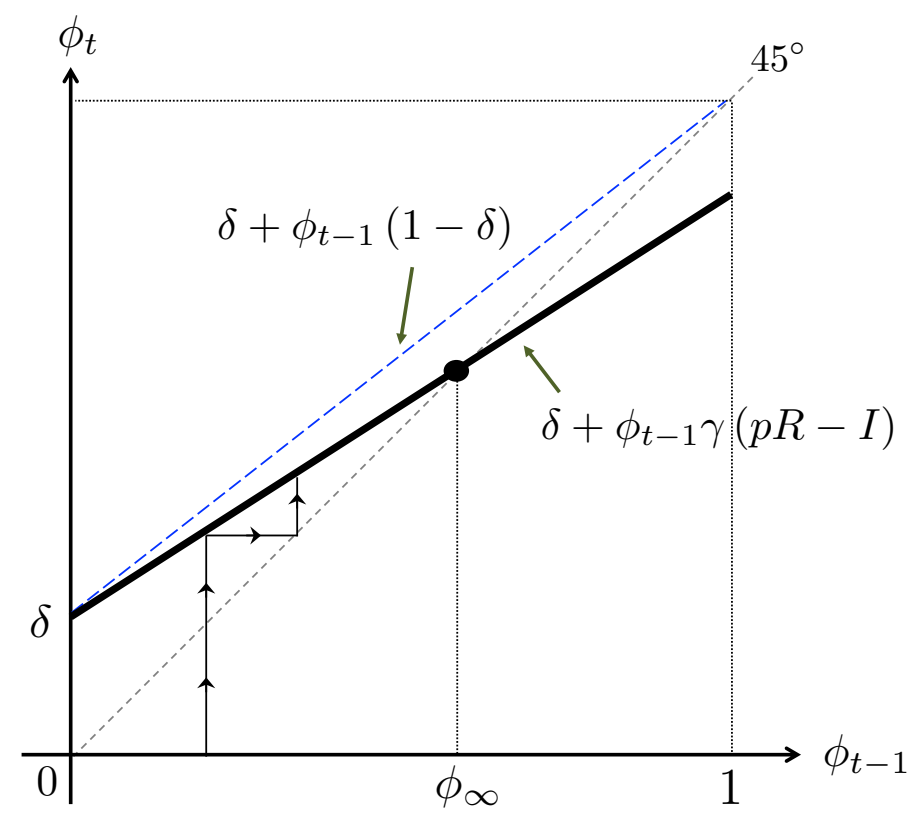

Figure 5: Dynamics in credit markets without adverse selection their optimal effort level does not exceed $1-\delta$, it is given by

$$
f_{t-1}^{G}=\gamma(p R-I)
$$

By substituting $f_{t-1}^{B}=0$ and (18) into (16), we completely characterize the evolution of trust: $\phi_{t}=\delta+\phi_{t-1} \gamma(p R-I)$. As shown in Figure 5, there exists a unique globally stable steady state.

Proposition 4 Suppose that entrepreneurs' type is observable and that Assumption 1 holds. If $p R-b^{G}+C \geq I$ and $\gamma(p R-I)<1-\delta$, then there exists a unique steady-state equilibrium where the level of trust is given by

$$
\phi_{\infty}=\frac{\delta}{1-\gamma(p R-I)}
$$

This unique steady-state equilibrium is globally stable, and starting from any $\phi_{0} \in(0,1), \phi_{t}$ monotonically converges to $\phi_{\infty}$. 


\subsection{Cultural transmission in credit markets with adverse selection}

Next, we analyze cultural transmission when entrepreneurs' type is private information. Since all decisions during the working phase are made separately from parental education, we can use the analysis of Section 3.2 and Section 3.3.

To simplify the following analysis, we make two assumptions. First, we assume

\section{Assumption 3}

$$
\underline{\phi}<\delta<\frac{1}{2}
$$

The right-hand side of Assumption 3 assures that given that $\delta$ is the minimum proportion of good entrepreneurs, bad entrepreneurs can constitute the majority. The left-hand side of Assumption 3 guarantees that on the equilibrium path, financing necessarily occurs. If $\delta<\underline{\phi}$, a steady state with $\phi_{t-1}=\phi_{t}=\delta$ always exists, where credit markets break down. Since the presence of such a steady state complicates the analysis and does not change our conclusion, we focus on the situation with $\underline{\phi} \leq \delta$. The second assumption is that

\section{Assumption 4}

$$
\frac{1}{2}<\frac{I}{p R-b^{G}}
$$

This assumption guarantees that even under the weak enforcement regime, the equilibrium level of enforcement is positive, namely $\tau_{t}>0$ for any $t$. If Assumption 4 is violated, there might exist multiple steady states under the weak enforcement regime. However, because such multiplicity is outside our interest, we rule out that case.

Under Assumption 3 and Assumption 4, given the current state variable $\phi_{t} \geq \delta$, the equilibrium level of enforcement is

$$
\tau_{t}=\tau\left(\phi_{t}\right)= \begin{cases}1 & \text { if } \frac{1}{2}<\phi_{t} \\ \max \left\{\frac{I-\phi_{t} p R}{C\left(1-\phi_{t}\right)}, \frac{I-\phi_{t}\left(p R-b^{G}\right)}{C}\right\} & \text { if } \frac{1}{2} \geq \phi_{t}\end{cases}
$$


from (10) and Proposition 3, and the equilibrium contract is

$$
\left(r_{t}, k_{t}\right)=\left(\frac{I-\left(1-\phi_{t} p\right) \tau\left(\phi_{t}\right) C}{\phi_{t} p}, 1\right)
$$

from Proposition 2. Correspondingly, the equilibrium payoffs of entrepreneurs with type $i \in\{G, B\}$ in the working phase are given by

$$
\begin{aligned}
& U_{t}^{G}=p R-\frac{I}{\phi_{t}}+\frac{1-\phi_{t}}{\phi_{t}} \tau\left(\phi_{t}\right) C, \\
& U_{t}^{B}=b^{B}-\tau\left(\phi_{t}\right) C,
\end{aligned}
$$

where (22) and (23) are derived from (13) and (14), respectively.

Then, consider the parental education problem (17). When the type of a parent and a child is the same (i.e., $i=j$ ), the parent receives the same utility as the child: $V_{t}^{G G}=U_{t}^{G}$ and $V_{t}^{B B}=U_{t}^{B}$. When the type of parent and child is different (i.e., $i \neq j$ ), the idea of imperfect empathy comes in:

$$
\begin{aligned}
V_{t}^{B G} & =p R-\frac{I}{\phi_{t}}+\frac{1-\phi_{t}}{\phi_{t}} \tau\left(\phi_{t}\right) C-\alpha^{B}, \\
V_{t}^{G B} & =b^{G}-\tau\left(\phi_{t}\right) C .
\end{aligned}
$$

(24) shows that bad parents consider that the investment undertaken by their good children entails the psychological cost $\alpha^{B}$. (25) shows that good parents consider cheating by their bad children to be shameful conduct and evaluate the private benefits as $b^{G}$ but not the benefits that their bad children indeed obtain $b^{B}$. Thus, we have $V_{t}^{G B} \neq V_{t}^{B B}$, which contrasts with the case without adverse selection $\left(V_{t}^{G B}=V_{t}^{B B}=0\right)$ because while no financing gives both types of old entrepreneurs the same payoff, cheating gives them different payoffs depending on their type.

We characterize the equilibrium level of educational effort. To ensure that it does not reach the upper bound, $1-\delta$, we assume 


\section{Assumption 5}

$$
\gamma<\frac{1-\delta}{p R-b^{G}-I+C}
$$

This assumption guarantees that on the equilibrium path, the level of trust $\phi_{t}$ is strictly lower than one and adverse selection is not resolved completely.

Lemma 1 Suppose that Assumptions 1-5 hold. For old entrepreneurs of type B, the optimal level of education is given by $f_{t-1}^{B}=0$ for any period. For old entrepreneurs of type $G$, it is given by

$$
f_{t-1}^{G}= \begin{cases}f_{s}\left(\phi_{t}\right) \equiv \gamma\left[p R-b^{G}-\frac{I-C}{\phi_{t}}\right] & \text { if } \frac{1}{2}<\phi_{t} \\ f_{w}\left(\phi_{t}\right) \equiv \max \left\{\gamma\left(\frac{I-\phi_{t} p R}{1-\phi_{t}}-b^{G}\right), 0\right\} & \text { if } \frac{1}{2} \geq \phi_{t}\end{cases}
$$

where $f_{s}\left(\phi_{t}\right)$ is increasing in $\phi_{t}$ and, if $\phi_{t}<\frac{I-b^{G}}{p R-b^{G}}, f_{w}\left(\phi_{t}\right)$ is decreasing in $\phi_{t}$.

Proof. See Appendix B.

Lemma 1 suggests that in equilibrium, only old entrepreneurs of type $G$ have incentives to exert educational effort. Thus, hereafter, we refer to them as just old entrepreneurs or parents.

The optimal level of education (26) differs from that without adverse selection (18) and thus creates different dynamics of trust. Without adverse selection, (18) indicates that the effort level is independent of parents' expectations about the future level of trust $\phi_{t}$ and the corresponding level of enforcement $\tau_{t}$. With adverse selection, (26) indicates that the future level of trust $\phi_{t}$ not only directly influences the optimal level of education, but also indirectly affects it through a change in enforcement quality $\tau\left(\phi_{t}\right)$. The effect from the future quality of enforcement to the current educational choices generates the mechanism through which the complementarity between trust and enforcement emerges.

From (26), when old entrepreneurs expect that $\phi_{t}>1 / 2$, so that the strong enforcement regime appears in the next period, there is cultural complementarity; that is, the optimal level 
of education $f_{s}\left(\phi_{t}\right)$ is increasing in $\phi_{t}$. This means that old entrepreneurs have more incentive to exert educational effort as they anticipate that young entrepreneurs of type $G$ will be more dominant in the population. A higher $\phi_{t}$ decreases the extent of cross-subsidization by good entrepreneurs and raises their payoff $U_{t}^{G}$ and their good parents' payoff $V_{t}^{G G}$, encouraging parental education.

(26) also indicates that when old entrepreneurs expect that $\phi_{t} \leq 1 / 2$ and the weak enforcement regime appears in the next period, there can be cultural substitution; that is, the educational level $f_{w}\left(\phi_{t}\right)$ is decreasing in $\phi_{t}$ if $\phi_{t}<\frac{I-b^{G}}{p R-b^{G}}$. Because a higher $\phi_{t}$ leads to weaker enforcement, which benefits type- $B$ children and hurts type- $G$ children, old entrepreneurs have less incentive to make educational effort as they anticipate that type- $G$ children will be

more dominant in the population. If $\phi_{t} \geq \frac{I-b^{G}}{p R-b^{G}}$, an old entrepreneur is indifferent between having a type- $G$ and a type- $B$ child $\left(V_{t}^{G G}=V_{t}^{G B}\right)$ and thus $f_{w}\left(\phi_{t}\right)=0$.

\subsection{Dynamic analysis: Steady states}

Substituting $f_{t-1}^{B}=0$ and (26) into (16) yields the following evolution of trust.

Lemma 2 Suppose that Assumptions 1-5 hold. Given $\phi_{t} \geq \delta$, $\phi_{t}$ evolves according to

$$
\phi_{t}= \begin{cases}\Upsilon^{-1}\left(\phi_{t-1}\right) & \text { if } \frac{1}{2}<\phi_{t}, \\ \Omega^{-1}\left(\phi_{t-1}\right) & \text { if } \frac{1}{2} \geq \phi_{t} \text { and } \delta \leq \phi_{t}<\frac{I-b^{G}}{p R-b^{G}} \\ \delta & \text { otherwise, }\end{cases}
$$

where

$$
\begin{aligned}
\Upsilon\left(\phi_{t}\right) & \equiv \frac{\left(\phi_{t}-\delta\right) \phi_{t}}{\gamma\left[\phi_{t}\left(p R-b^{G}\right)-(I-C)\right]}, \\
\Omega\left(\phi_{t}\right) & \equiv \frac{\left(\phi_{t}-\delta\right)\left(1-\phi_{t}\right)}{\gamma\left[I-b^{G}-\phi_{t}\left(p R-b^{G}\right)\right]} .
\end{aligned}
$$

1. $\Upsilon(\delta)=0$ and $\Upsilon(1)>1$. For any $\phi_{t} \geq \delta, \Upsilon^{\prime}\left(\phi_{t}\right)>0$ and $\Upsilon^{\prime \prime}\left(\phi_{t}\right)<0$. 


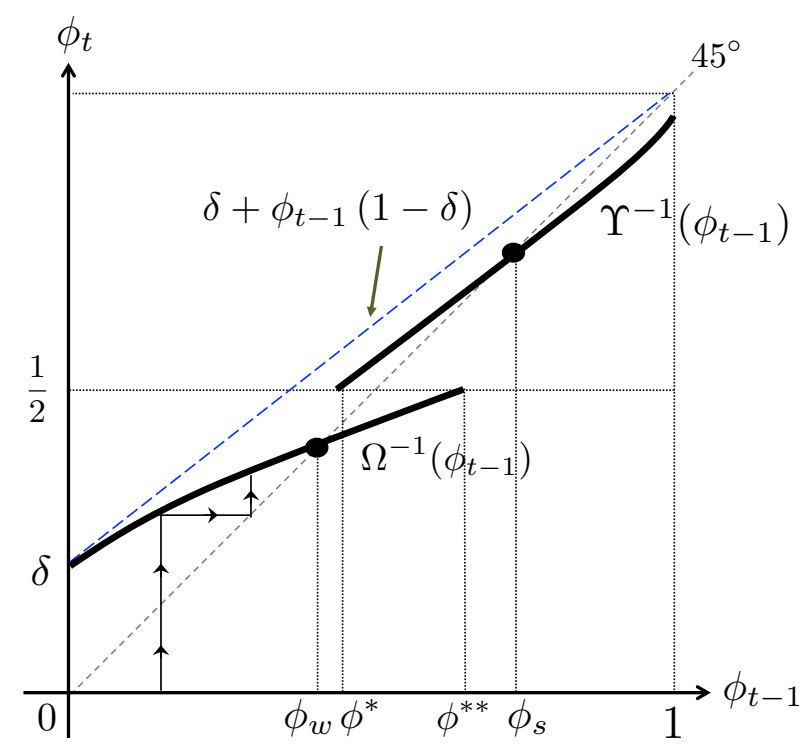

(a) $\delta<\frac{I-b^{G}}{p R-b^{G}}$

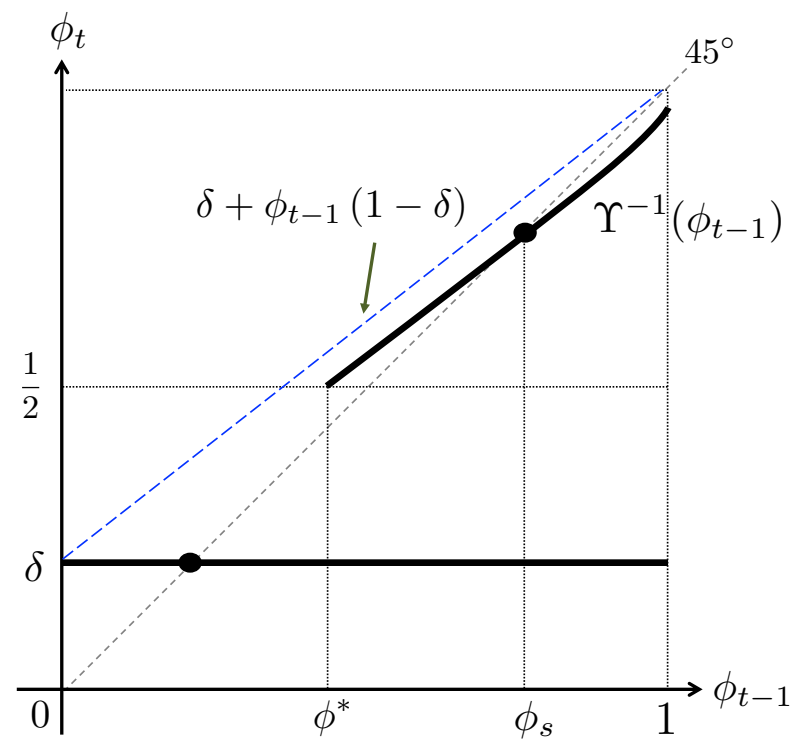

(b) $\delta \geq \frac{I-b^{G}}{p R-b^{G}}$

Figure 6: Multiple stable steady states

2. $\Omega(\delta)=0$ and as $\phi_{t} \rightarrow \frac{I-b^{G}}{p R-b^{G}}, \Omega\left(\phi_{t}\right) \rightarrow \infty$. For any $\phi_{t} \in\left[\delta, \frac{I-b^{G}}{p R-b^{G}}\right), \Omega^{\prime}\left(\phi_{t}\right)>0$ and $\Omega^{\prime \prime}\left(\phi_{t}\right)>0$.

Proof. See Appendix C.

Lemma 2 characterizes the complete dynamics of trust, as shown in Figure 6. From (27), if old entrepreneurs of generation $t-1$ expect $\phi_{t}>\frac{1}{2}$ and exert the educational effort $f_{s}\left(\phi_{t}\right)$ given by (26), the condition $\phi_{t}=\Upsilon^{-1}\left(\phi_{t-1}\right)>\frac{1}{2}$ must hold. Given that $\Upsilon^{-1}$ is increasing in $\phi_{t}$, the current level of trust $\phi_{t-1}$ must be sufficiently high such that $\phi_{t-1}>\Upsilon\left(\frac{1}{2}\right) \equiv \phi^{*}>0$. Moreover, if $\phi^{*}<\frac{1}{2}$, or

$$
\frac{1-2 \delta}{\gamma}+b^{G}<p R-2(I-C)
$$

then the dynamic equation under the strong enforcement regime leads to a unique steady state at which the level of trust is such that $\phi_{s}=\Upsilon\left(\phi_{s}\right)$.

(27) also implies that if old entrepreneurs of generation $t-1$ expect $\phi_{t} \leq \frac{1}{2}$ and exert the educational effort $f_{w}\left(\phi_{t}\right)$ given by (26), the dynamics change depending on certain parameters. When $\delta<\frac{I-b^{G}}{p R-b^{G}}$ and the expected level of trust $\phi_{t}$ is in the range $\left[\delta, \frac{I-b^{G}}{p R-b^{G}}\right)$, the 
condition $\phi_{t}=\Omega^{-1}\left(\phi_{t-1}\right) \leq \frac{1}{2}$ must hold. ${ }^{15}{ }^{16}$ Given that $\Omega^{-1}$ is increasing in $\phi_{t}$, the current level of trust $\phi_{t-1}$ must be sufficiently low such that $\phi_{t-1} \leq \min \left\{\Omega\left(\frac{1}{2}\right), 1\right\} \equiv \phi^{* *}$. Moreover, if $\phi^{* *} \geq \frac{1}{2}$, or

$$
2 I-p R \leq \frac{1-2 \delta}{\gamma}+b^{G}
$$

the dynamic equation under the weak enforcement regime yields a unique steady state at which the level of trust is such that $\phi_{w}=\Omega\left(\phi_{w}\right)$, as shown in Figure $6 \mathrm{a}$. When $\delta \geq \frac{I-b^{G}}{p R-b^{G}}$, $\phi_{t}$ must be $\delta$ for any current level of trust $\phi_{t-1}$, and thus $\delta$ is a unique steady-state level of trust under the weak enforcement regime, as shown in Figure 6b.

The following proposition characterizes the existence of multiple steady states:

\section{Proposition 5 Suppose that Assumptions 1-5 hold. Two steady states exist}

(i) if (30) and (31) hold and $\delta<\frac{I-b^{G}}{p R-b^{G}}$, where the one steady-state level of trust is such that $\phi_{s}=\Upsilon\left(\phi_{s}\right)$ and the other one is such that $\phi_{w}=\Omega\left(\phi_{w}\right)$; or

(ii) if (30) holds and $\delta \geq \frac{I-b^{G}}{p R-b^{G}}$, where the one steady-state level of trust is such that $\phi_{s}=\Upsilon\left(\phi_{s}\right)$ and the other one is given by $\delta$.

In either case, one has greater trust, stronger enforcement, lower repayment, and higher aggregate output than the other.

Proposition 5 establishes that across these multiple steady states, there is a positive relationship among the level of trust, quality of enforcement, degree of financial development (measured by the cost of external financing $r$ ), and level of aggregate output. This result is consistent with the observed variation across countries or regions, as shown in Tabellini (2008a) and Algan and Cahuc (2014, Tables 2.6a).

These multiple steady states are due to the complementarity between trust and enforcement stemming from the presence of adverse selection. Proposition 4 suggests that without

\footnotetext{
${ }^{15}$ It also must be that $\Omega^{-1}\left(\phi_{t-1}\right)<\frac{I-b^{G}}{p R-b^{G}}$. However, this condition is satisfied for any $\phi_{t-1}$ from Lemma 2 .

${ }^{16}$ When $\delta<\frac{I-b^{G}}{p R-b^{G}}, \phi_{t}$ is not in the range $\left[\frac{I-b^{G}}{p R-b^{G}}, \frac{1}{2}\right]$ in equilibrium, because if old entrepreneurs expect $\phi_{t} \in\left[\frac{I-b^{G}}{p R-b^{G}}, \frac{1}{2}\right]$, from (27), the condition $\phi_{t}=\delta \geq \frac{I-b^{G}}{p R-b^{G}}$ must hold, which is a contradiction.
} 
adverse selection, old entrepreneurs' educational effort is not influenced by their expectations about institutional quality, so that there is no interaction between trust and enforcement, leading to a unique steady state. However, with adverse selection, the quality of enforcement affects the payoffs of both types of entrepreneurs; accordingly, old entrepreneurs' educational choice is influenced by their expectations about future enforcement quality. In a high-trust (low-trust) steady state, old entrepreneurs anticipate that the strong (weak) enforcement regime appears and exert a high (low) level of civic education, so that the resulting economy achieves a high (low) level of trust and supports the strong (weak) enforcement regime through the political process.

\subsection{Dynamic analysis: Transitional dynamics}

Figure 6 suggests that both the initial level of trust $\phi_{0}$ and parents' expectations play a role in selecting the steady state at which the economy will end up. If $\phi_{w} \leq \phi^{*}$, in an economy with the initial level of trust $\phi_{0} \leq \phi^{*}$, a unique equilibrium path converges to the steady state represented by $\phi_{w}$, along which the weak enforcement regime persists. If $\phi_{s}>\phi^{* *}$, in an economy with the initial level of trust $\phi_{0}>\phi^{* *}$, a unique equilibrium path converges to the steady state represented by $\phi_{s}$, along which the strong enforcement regime persists. In these situations, preconditions determine the equilibrium path and resulting steady state.

Otherwise, multiple equilibria are possible. Once $\phi_{t}$ reaches the region in which both regimes are possible, that is, $\left(\phi^{*}, \phi^{* *}\right]$ when $\delta<\frac{I-b^{G}}{p R-b^{G}}$ and $\left(\phi^{*}, 1\right]$ when $\delta \geq \frac{I-b^{G}}{p R-b^{G}}$, parents' expectations determine the equilibrium path. If a parent anticipates that other parents exert high levels of educational effort so that the strong enforcement regime appears in the next period, the parent also exerts high levels of educational effort, resulting in the hightrust economy. If, instead, a parent anticipates that other parents exert low educational effort so that the weak enforcement regime prevails in the next period, the parent also exerts low educational effort, thus leading to the low-trust economy. These results imply that expectations matter in selecting the steady state in which the economy will eventually 
reach.

Proposition 6 Suppose that multiple steady states exist. If $\phi_{w} \leq \phi^{*}$, starting from any $\phi_{0} \leq \phi^{*}, \phi_{t}$ monotonically converges to $\phi_{w}$. If $\phi_{s}>\phi^{* *}$, starting from any $\phi_{0}>\phi^{* *}, \phi_{t}$ monotonically converges to $\phi_{s}$. Otherwise, both steady states can be reached.

Proposition 6 resonates with the empirical findings on the persistent effects of historic shocks on levels of trust, institutions, and economic development. When a positive historic shock such as the free city-states' experience in the Italian Middle Ages (Putnam, 1993 and Guiso et al., 2016) or a negative historic shock such as Africa's slave trade (Nunn and Wantchekon, 2011) influences beliefs in the trustworthiness in society, the resulting trust persists in the long run and has long-lasting effects on economic development. Our model suggests that a historic shock that cultivates (destroys) trust is long-lasting because it leads to strong (weak) enforcement through the political process, which in turn encourages (discourages) the formation of trust through parental education.

La Porta et al. $(1998,2008)$ emphasize the influence of the legal origin on the legal protection of investors and the degree of financial development. French civil law countries are more likely to adopt weak legal protection and have less developed financial markets than English common law countries. Our model helps explain this legal origin theory based on La Porta et al.'s (2008) argument that the French civil law system embeds the beliefs that a country needs to be concerned with private disorder, whereas a common law system embeds the beliefs that private citizens are so peaceful that the country needs to be less concerned with disorder. According to such a view, while the transplantation of civic law through conquest and colonization changes peoples' mindsets and brings about distrust in other people, the transplantation of common law encourages the formation of trust in others. Therefore, by interpreting the transplantation of civil (common) law as a trust-destroying (trust-building) historic shock, we can argue that such a shock has a long-lasting effect on institutions through the political process and parents' education choices.

Moreover, Proposition 6 has a novel empirical implication. Our finding is that whether 
trust and legal enforcement are complements or substitutes depends on the timespan. In the long run, the economy reaches one of the steady states, showing that trust and enforcement are complements. In the short run, however, trust and enforcement may be substitutes. Along the adjustment path converging to the steady state $\phi_{w}$, greater trust, which allows good entrepreneurs to obtain financing with better conditions, leads bad entrepreneurs to weaken enforcement further and increase their rents.

\subsection{Comparative statics}

We first consider the effect of technological change (i.e., an increase in $R$ ). Figure 7 a depicts its effect on the evolution of trust. In the strong enforcement regime, the increase in $R$ raises the profitability of running a project and encourages parental education (26). The steady-state level of trust $\phi_{s}$ and corresponding aggregate output are higher. In the weak enforcement regime, however, bad entrepreneurs take advantage of the beneficial effects of a higher $R$ on good entrepreneurs by weakening enforcement, as shown in Figure 3a. The weaker enforcement benefits bad entrepreneurs and damages good entrepreneurs, discouraging educational effort (26) and the formation of trust. The steady-state level of trust $\phi_{w}$ then decreases and this undermines the positive effect of the increase in $R$ on aggregate output. Such negative impacts of technological improvement on the formation of trust are in sharp contrast to the case without adverse selection, where a higher $R$ always cultivates trust from Proposition 4.

These results imply that technological progress exacerbates the level of inequality in trust, institutions, and aggregate output between steady states. The economy that reaches the high-trust steady state cultivates trust further, whereas the economy that ends up in the low-trust steady state suffers from lower institutional quality and a more severe trust deficit. This result may help explain why even though ideas and knowledge can spread so rapidly that any country has access to the innovations developed in advanced countries, there is still a large disparity between advanced and developing countries. 


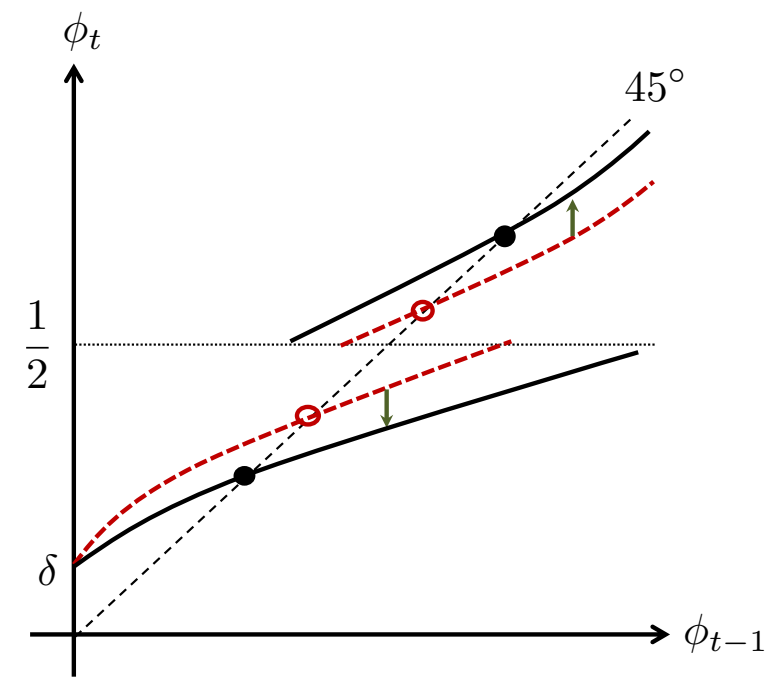

(a) The effect of an increase in $R$

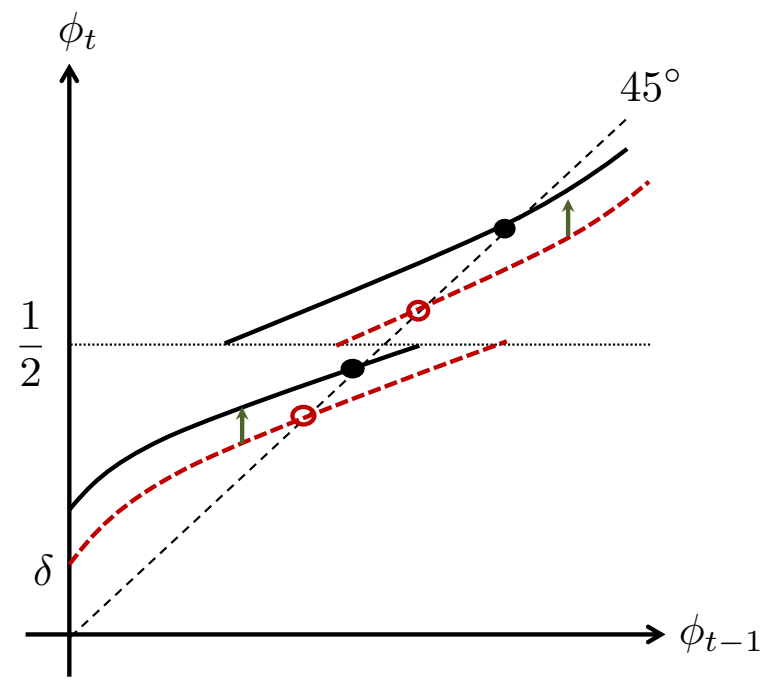

(b) The effect of a decrease in $b^{G}$

Figure 7: Comparative statics in the dynamic model

Moreover, after the increase in $R$, the region in which the enforcement regime in the next period depends on expectations, $\left(\phi^{*}, \phi^{* *}\right]$, widens. This implies that in a narrower range of the initial level of trust, the precondition matters in selecting the steady state in which the economy will end up. Technological innovations increase the relative importance of expectations over the initial condition.

Then, we consider the effect of public education captured by an increase in the feeling of guilt from cheating $\beta^{G}$ or a decrease in $b^{G}$. Because good parents incur a higher psychological cost when their bad children cheat, they spend more educational effort in either enforcement regime from (26). Thus, as shown in Figure 7b, the steady-state levels of trust $\phi_{s}$ and $\phi_{w}$ increase. The higher $\phi_{w}$ leads to a decrease in enforcement quality in the weak enforcement regime, although Figure $3 \mathrm{~b}$ shows that a decrease in $b^{G}$ does not directly affect enforcement quality when $\phi_{t}<\frac{I-b^{G}}{p R-b^{G}}$. If there is no adverse selection, these effects of public education are absent from Proposition 4.

This implies that public education might play an important role in eliminating the underdevelopment trap. If the decrease in $b^{G}$ is sufficiently large, the economy that has been trapped in the low-trust steady state jumps on the path toward a high-trust steady state, 
and eventually the initial inequality between steady states vanishes.

Proposition 7 We examine the following comparative statics.

1. Suppose that $R$ increases. $\phi_{s}$ increases, and $\phi_{w}$ and $\tau\left(\phi_{w}\right)$ decrease. Moreover, the width of the region, $\left(\phi^{*}, \phi^{* *}\right]$, increases.

2. Suppose that $\beta^{G}$ increases, or $b^{G}$ decreases. $\phi_{s}$ and $\phi_{w}$ increase, and $\tau\left(\phi_{w}\right)$ decreases.

Proof. See Appendix D.

\section{Concluding Remarks}

This study examines the coevolution of trust and legal enforcement in a model of competitive credit markets with asymmetric information. The presence of adverse selection leads civic entrepreneurs to cross-subsidize uncivic ones, generates a conflict of interests between different types of entrepreneurs over the quality of enforcement, and influences the formation of trust. Legal enforcement and trust may be substitutes in the short run but they are complements in the long run, leading to multiple steady states with different levels of enforcement quality, trust, and aggregate output. While the impact of technological improvement on an underdeveloped economy may be dampened due to uncivic entrepreneurs' rent-seeking, public education has the potential to drive the economy out of the trap.

We conclude with remarks on issues not covered in any depth in this study. While in our model, the quality of legal enforcement evolves endogenously, we do not consider the dynamic linkage of institutional quality. However, current institutional quality could affect future institutional quality because an adjustment cost is present or the distribution of political power changes. Such a dynamic analysis is a promising area for future research.

From a policy perspective, our model suggests that public education may be helpful to eliminate an underdevelopment trap. However, the provision of public schooling could be the result of a political decision. In that context, uncivic citizens that constitute the 
majority might disagree with investment in public education because they fear that this policy increases the proportion of civic citizens and causes a shift in political power to them. The political economy of public education is thus also an important issue for understanding the formation of trust.

\section{Appendix A Proof of Proposition 2}

Proof. From (8) and (9), financing occurs if $\tau$ is sufficiently large such that

$$
\tau C \geq \Psi_{1}(\phi) \equiv I-\phi\left(p R-b^{G}\right) \quad \text { and } \quad \tau C \geq \Psi_{2}(\phi) \equiv \frac{I-\phi p R}{1-\phi}
$$

We have $\Psi_{1}^{\prime}<0, \Psi_{1}^{\prime \prime}=0, \Psi_{2}^{\prime}=-\frac{p R-I}{(1-\phi)^{2}}<0, \Psi_{2}^{\prime \prime}<0$, and $\lim _{\phi \rightarrow 1} \Psi_{2}=-\infty$. $\Psi_{1}$ and $\Psi_{2}$ cross at two points, 0 and $\frac{I-b^{G}}{p R-b^{G}} \in\left(0, \frac{I}{p R-b^{G}}\right)$. When $\phi \in\left[0, \frac{I-b^{G}}{p R-b^{G}}\right]$, we have $\Psi_{2} \geq \Psi_{1}$. When $\phi \in\left(\frac{I-b^{G}}{p R-b^{G}}, 1\right]$, we have $\Psi_{2}<\Psi_{1}$.

If $\phi<\underline{\phi}$, then $\max \left\{\Psi_{1}, \Psi_{2}\right\}>C$, which implies that (32) is violated for any $\tau$, and no financing occurs. Then, suppose $\underline{\phi} \leq \phi$, which implies $\max \left\{\Psi_{1}, \Psi_{2}\right\} \leq C$. If $\phi \leq \frac{I-b^{G}}{p R-b^{G}},(32)$ holds for any $\tau \geq \underline{\tau}(\phi)=\Psi_{2}(\phi) / C$. If $\frac{I-b^{G}}{p R-b^{G}}<\phi \leq \frac{I}{p R-b^{G}}$, (32) holds for any $\tau \geq \underline{\tau}(\phi)=$ $\Psi_{1}(\phi) / C$. If $\frac{I}{p R-b^{G}}<\phi$, then $\max \left\{\Psi_{1}, \Psi_{2}\right\}<0$ so that (32) holds for any $\tau$.

\section{Appendix B Proof of Lemma 1}

Proof. For old entrepreneurs of type $B$, from Assumption 1 we have $V_{t}^{B G}<V_{t}^{B B}$ and thus $f_{t-1}^{B}=0$ for any period. For old entrepreneurs of type $G$, the optimal level of education is given by

$$
f_{t-1}^{G}=\frac{\gamma}{\phi_{t}}\left[\phi_{t}\left(p R-b^{G}\right)+\tau\left(\phi_{t}\right) C-I\right]
$$

from (22) and (25).

If $\phi_{t}>\frac{1}{2}, \tau\left(\phi_{t}\right)=1$ from (20), so that (33) becomes $f_{s}\left(\phi_{t}\right)$, where $f_{s}$ is increasing in $\phi_{t}$. Because $f_{s}(1)<1-\delta$ from Assumption 5 , it is shown that $f_{s}\left(\phi_{t}\right)<1-\delta$ for any $\phi_{t}>\frac{1}{2}$. 
If $\phi_{t} \leq \frac{1}{2}$, combining (20) and (33) yields the effort level given by $f_{w}\left(\phi_{t}\right) . f_{w}$ is positive and decreasing in $\phi_{t}$ if $\phi_{t}<\frac{I-b^{G}}{p R-b^{G}}$ and is zero if $\phi_{t} \geq \frac{I-b^{G}}{p R-b^{G}}$. Here, to assure that $f_{w}\left(\phi_{t}\right)<1-\delta$ for any $\phi_{t} \in\left[\delta, \frac{1}{2}\right]$, it is sufficient to show that $f_{w}(\delta)<1-\delta$. This is the case because $f_{s}(1)<1-\delta$ from Assumption 5 and

$$
f_{s}(1)-f_{w}(\delta) \geq \frac{\gamma}{1-\delta}\{p R-I-(1-\delta)(I-C)\}>0,
$$

where the second inequality holds from Assumption 3, which implies that $p R-I>I-C$.

\section{Appendix C Proof of Lemma 2}

Proof. First, suppose that $\phi_{t}>\frac{1}{2}$. (16) can be rewritten as $\phi_{t-1}=\frac{\phi_{t}-\delta}{f_{s}\left(\phi_{t}\right)}=\Upsilon\left(\phi_{t}\right)$. Under Assumption 5, we have $\Upsilon\left(\phi_{t}\right)>\frac{\phi_{t}-\delta}{1-\delta}$, which implies that $\Upsilon(1)>1$. For any $\phi_{t} \in[\delta, 1)$,

$$
\begin{gathered}
\Upsilon^{\prime}\left(\phi_{t}\right)=\frac{\phi_{t}^{2}\left(p R-b^{G}\right)-\left(2 \phi_{t}-\delta\right)(I-C)}{\gamma\left[\phi_{t}\left(p R-b^{G}\right)-(I-C)\right]^{2}}>0 \\
\Upsilon^{\prime \prime}\left(\phi_{t}\right)=\frac{-2(I-C)\left[\delta\left(p R-b^{G}\right)-(I-C)\right]}{\gamma\left[\phi_{t}\left(p R-b^{G}\right)-(I-C)\right]^{3}}<0
\end{gathered}
$$

because $\delta>\underline{\phi} \geq \frac{I-C}{p R-b^{G}}$ from Assumption 3 and (11). Thus, we have $\phi_{t}=\Upsilon^{-1}\left(\phi_{t-1}\right)$, where $\Upsilon^{-1}\left(\phi_{t-1}\right)$ is increasing and convex in $\phi_{t-1}$.

Next, suppose that $\phi_{t} \leq \frac{1}{2}$. If $\delta \leq \phi_{t}<\frac{I-b^{G}}{p R-b^{G}}$, we have $f_{w}\left(\phi_{t}\right)>0$, and (16) boils down to $\phi_{t-1}=\frac{\phi_{t}-\delta}{f_{w}\left(\phi_{t}\right)}=\Omega\left(\phi_{t}\right)$. Because $\frac{I-b^{G}}{p R-b^{G}}<1$ from Assumption 1, for any $\phi_{t} \in\left[\delta, \frac{I-b^{G}}{p R-b^{G}}\right)$,

$$
\begin{aligned}
\Omega^{\prime}\left(\phi_{t}\right) & =\frac{\left(-2 \phi_{t}+1+\delta\right)\left[I-b^{G}-\phi_{t}\left(p R-b^{G}\right)\right]+\left(\phi_{t}-\delta\right)\left(1-\phi_{t}\right)\left(p R-b^{G}\right)}{\gamma\left[I-b^{G}-\phi_{t}\left(p R-b^{G}\right)\right]^{2}} \\
& =\frac{\left(1-\phi_{t}\right)\left[I-b^{G}-\phi_{t}\left(p R-b^{G}\right)\right]+\left(\phi_{t}-\delta\right)(p R-I)}{\gamma\left[I-b^{G}-\phi_{t}\left(p R-b^{G}\right)\right]^{2}}>0,
\end{aligned}
$$


and

$\Omega^{\prime \prime}\left(\phi_{t}\right)=\frac{2}{\gamma\left[I-b^{G}-\phi_{t}\left(p R-b^{G}\right)\right]^{2}}\left\{p R-I+\left(p R-b^{G}\right)\left(1-\phi_{t}+\frac{\left(\phi_{t}-\delta\right)(p R-I)}{I-b^{G}-\phi_{t}\left(p R-b^{G}\right)}\right)\right\}>0$.

Thus, we have $\phi_{t}=\Omega^{-1}\left(\phi_{t-1}\right)$, where $\Omega^{-1}\left(\phi_{t-1}\right)$ is increasing and concave in $\phi_{t-1}$.

Otherwise, $f_{w}\left(\phi_{t}\right)=0$, leading to $\phi_{t}=\delta$.

\section{Appendix D Proof of Proposition 7}

Proof. First, suppose that $R$ increases. From Lemma 2, $\Upsilon\left(\phi_{t}\right)$ decreases, implying that $\phi^{*}=$

$\Upsilon\left(\frac{1}{2}\right)$ decreases and $\phi_{s}$ increases, and $\Omega\left(\phi_{t}\right)$ increases, implying that $\phi^{* *}=\min \left\{\Omega\left(\frac{1}{2}\right), 1\right\}$

increases or does not change. It is also shown that $\phi_{w}$ decreases; totally differentiating $\phi_{w}=\Omega\left(\phi_{w}\right)$ with respect to $\phi_{w}$ and $R$ yields

$$
\begin{aligned}
\frac{\partial \phi_{w}}{\partial R} & =-\frac{\partial \Omega\left(\phi_{w}\right)}{\partial R} \frac{1}{\Omega^{\prime}\left(\phi_{w}\right)-1} \\
& =\frac{-\phi_{w} p\left(1-\phi_{w}\right)\left(\phi_{w}-\delta\right)}{\left(1-\phi_{w}\right)\left[I-b^{G}-\phi_{w}\left(p R-b^{G}\right)\right]+\left(\phi_{w}-\delta\right)(p R-I)-\gamma\left[I-b^{G}-\phi_{w}\left(p R-b^{G}\right)\right]^{2}} \\
& =\frac{-\phi_{w} p}{\delta\left(1-\phi_{w}\right) /\left(\gamma \phi_{w}^{2}\right)+(p R-I) /\left(1-\phi_{w}\right)}<0,
\end{aligned}
$$

where the second equality is derived from (34) and the third equality is derived from the definition that $\phi_{w}=\Omega\left(\phi_{w}\right)$. From (20) and (35), we also have

$$
\begin{aligned}
\frac{\partial \tau\left(\phi_{w}\right)}{\partial R} & =\frac{\partial}{\partial R}\left[\frac{I-\phi_{w} p R}{C\left(1-\phi_{w}\right)}\right]=\frac{p \phi_{w}}{C\left(1-\phi_{w}\right)}\left(-1-\frac{p R-I}{\left(1-\phi_{w}\right) \phi_{w} p} \frac{\partial \phi_{w}}{\partial R}\right) \\
& =\frac{p \phi_{w}}{C\left(1-\phi_{w}\right)}\left(-1+\frac{\gamma \phi_{w}^{2}(p R-I)}{\delta\left(1-\phi_{w}\right)^{2}+\gamma \phi_{w}^{2}(p R-I)}\right)<0 .
\end{aligned}
$$

Then, suppose that $\beta^{G}$ increases, that is, $b^{G}$ decreases. From (28) and Lemma $2, \Upsilon\left(\phi_{t}\right)$ decreases and $\phi_{s}$ increases. From (29) and Lemma $2, \Omega\left(\phi_{t}\right)$ decreases and $\phi_{w}$ increases. It is also shown that $\tau\left(\phi_{w}\right)$ decreases because from $(20) \tau\left(\phi_{w}\right)=\frac{I-\phi_{w} p R}{C\left(1-\phi_{w}\right)}$ is decreasing in $\phi_{w}$. 


\section{References}

Aghion, Philippe, Yann Algan, and Pierre Cahuc, "Civil society and the state: The interplay between cooperation and minimum wage regulation," Journal of the European Economic Association, 2011, 9 (1), 3-42.

_, _, _, and Andrei Shleifer, "Regulation and Distrust," The Quarterly Journal of Economics, 2010, 125 (3), 1015-1049.

Alesina, Alberto and George-Marios Angeletos, "Fairness and Redistribution," American Economic Review, 2005, 95 (4), 960-980.

_ and Paola Giuliano, "Culture and Institutions," Journal of Economic Literature, 2015, $53(4), 898-944$.

_, Yann Algan, Pierre Cahuc, and Paola Giuliano, "Family values and the regulation of labor," Journal of the European Economic Association, 2015, 13 (4), 599-630.

Algan, Yann and Pierre Cahuc, "Inherited Trust and Growth," American Economic Review, December 2010, 100 (5), 2060-92.

_ and _, "Trust, Growth, and Well-Being: New Evidence and Policy Implications," in Philippe Aghion and Steven N. Durlauf, eds., Handbook of Economic Growth, Vol. 2 of Handbook of Economic Growth, Elsevier, 2014, chapter 2, pp. 49 - 120.

Aney, Madhav S., Maitreesh Ghatak, and Massimo Morelli, "Credit market frictions and political failure," Journal of Monetary Economics, 2016, 81, 48 - 64.

Baumol, William J., "Entrepreneurship: Productive, Unproductive, and Destructive," Journal of Political Economy, 1990, 98 (5, Part 1), 893-921.

Bénabou, Roland and Jean Tirole, "Belief in a Just World and Redistributive Politics," The Quarterly Journal of Economics, 2006, 121 (2), 699-746. 
Besanko, David and Anjan V Thakor, "Competitive equilibrium in the credit market under asymmetric information," Journal of Economic Theory, 1987, 42 (1), 167 - 182.

Besley, Timothy, Konrad B. Burchardi, and Maitreesh Ghatak, "Incentives and the De Soto Effect," The Quarterly Journal of Economics, 2012, 127 (1), 237-282.

Bester, Helmut, "Screening vs. Rationing in Credit Markets with Imperfect Information," American Economic Review, September 1985, 75 (4), 850-855.

_ , "The role of collateral in credit markets with imperfect information," European Economic Review, 1987, 31 (4), 887 - 899. Special Issue on Market Competition, Conflict and Collusion.

Biais, Bruno and Thomas Mariotti, "Credit, wages, and bankruptcy laws," Journal of the European Economic Association, 2009, 7 (5), 939-973.

Bidner, Chris and Patrick Francois, "Cultivating Trust: Norms, Institutions and the Implications of Scale*," The Economic Journal, 2011, 121 (555), 1097-1129.

Bisin, Alberto and Thierry Verdier, "The economics of cultural transmission and the dynamics of preferences," Journal of Economic Theory, 2001, 97 (2), 298-319.

_ and _ , "On the Joint Evolution of Culture and Institutions," Working Paper 23375, National Bureau of Economic Research April 2017.

Carlin, Bruce Ian, Florin Dorobantu, and Sean Viswanathan, "Public trust, the law, and financial investment," Journal of Financial Economics, 2009, 92 (3), 321-341.

de Meza, David and David C. Webb, "Too Much Investment: A Problem of Asymmetric Information*," The Quarterly Journal of Economics, 1987, 102 (2), 281-292.

Djankov, Simeon, Caralee McLiesh, and Andrei Shleifer, "Private credit in 129 countries," Journal of financial Economics, 2007, 84 (2), 299-329. 
Francois, Patrick and Jan Zabojnik, "Trust, Social Capital, and Economic Development," Journal of the European Economic Association, 2005, 3 (1), 51-94.

Fukuyama, Francis, Trust: The Social Virtues and the Creation of Prosperity, New York: Free Press, 1995.

Gambetta, Diego, "Can We Trust Trust?," in Diego Gambetta, ed., Trust: Making and Breaking Cooperative Relations, University of Oxford, 2000, chapter 13, pp. 213-237.

Guiso, Luigi, Paola Sapienza, and Luigi Zingales, "The Role of Social Capital in Financial Development," American Economic Review, 2004, 94 (3), 526-556.

_, _, and _, "Long-term Persistence," Journal of the European Economic Association, 2016, 14 (6), 1401-1436.

Hauk, Esther and Maria Saez-Marti, "On the Cultural Transmission of Corruption," Journal of Economic Theory, 2002, 107 (2), 311 - 335.

Knack, Stephen and Philip Keefer, "Does Social Capital Have an Economic Payoff? A Cross-Country Investigation," The Quarterly Journal of Economics, 1997, 112 (4), 12511288.

Kumar, Krishna B. and John G. Matsusaka, "From Families to Formal Contracts: An Approach to Development," Journal of Development Economics, 2009, 90 (1), 106 - 119.

La Porta, Rafael, Florencio Lopez-de-Silanes, and Andrei Shleifer, "The Economic Consequences of Legal Origins," Journal of Economic Literature, 2008, 46 (2), 285-332.

_ , _ , , and Robert Vishny, "Law and Finance," Journal of Political Economy, 1998, $106(6), 1113-11$.

_, Florencio Lopez de Silanes, Andrei Shleifer, and Robert W Vishny, "Trust in Large Organizations," The American Economic Review, 1997, pp. 333-338. 
Martin, Alberto, "A model of collateral, investment, and adverse selection," Journal of Economic Theory, 2009, 144 (4), 1572 - 1588.

Matsuoka, Tarishi, Katsuyuki Naito, and Keigo Nishida, "The Politics of Financial Development and Capital Accumulation," Macroeconomic Dynamics, forthcoming.

Michau, Jean-Baptiste, "Unemployment Insurance and Cultural Transmission: Theory And Application To European Unemployment," Journal of the European Economic Association, 2013, 11 (6), 1320-1347.

Murphy, Kevin M., Andrei Shleifer, and Robert W. Vishny, "The Allocation of Talent: Implications for Growth*," The Quarterly Journal of Economics, 1991, 106 (2), 503.

Nunn, Nathan and Leonard Wantchekon, "The Slave Trade and the Origins of Mistrust in Africa," American Economic Review, 2011, 101 (7), 3221-52.

Pagano, Marco and Paolo F. Volpin, "The Political Economy of Corporate Governance," American Economic Review, September 2005, 95 (4), 1005-1030.

_ and Paolo Volpin, "Alfred Marshall Lecture Shareholder Protection, Stock Market Development, and Politics," Journal of the European Economic Association, 2006, 4 (2-3), $315-341$.

Perotti, Enrico C and Ernst-Ludwig von Thadden, "The political economy of corporate control and labor rents," Journal of Political Economy, 2006, 114 (1), 145-175.

Putnam, Robert D, Making democracy work: Civic traditions in modern Italy, Princeton, NJ: Princeton University Press, 1993.

Rajan, Raghuram G and Luigi Zingales, "The Great Reversals: The Politics of Financial Development in the Twentieth Century," Journal of Financial Economics, 2003, 69 (1), 5 -50 . 
Rothschild, Michael and Joseph Stiglitz, "Equilibrium in Competitive Insurance Markets: An Essay on the Economics of Imperfect Information," The Quarterly Journal of Economics, 1976, 90 (4), 629-649.

Ševčík, Pavel, "Financial contracts and the political economy of investor protection," American Economic Journal: Macroeconomics, 2012, 4 (4), 163-197.

Tabellini, Guido, "Presidential Address: Institutions and Culture," Journal of the European Economic Association, 2008, 6 (2-3), 255-294.

_ , "The Scope of Cooperation: Values and Incentives," The Quarterly Journal of Economics, 2008, $123(3), 905-950$.

_ , "Culture and Institutions: Economic Development in the Regions of Europe," Journal of the European Economic Association, 2010, 8 (4), 677-716. 